Provendo resiliência em uma rede de sensores sem fio linear e esparsa através de veículo aéreo não tripulado 



\title{
Provendo resiliência em uma rede de sensores sem fio linear e esparsa através de veículo aéreo não tripulado
}

\author{
Heitor de Freitas Vieira
}

Orientador: Prof. Dr. Jó Ueyama

Dissertação apresentada ao Instituto de Ciências Matemáticas e de Computação - ICMC-USP, como parte dos requisitos para obtenção do título de Mestre em Ciências - Ciências de Computação e Matemática Computacional. VERSÃO REVISADA 
Ficha catalográfica elaborada pela Biblioteca Prof. Achille Bassi e Seção Técnica de Informática, ICMC/USP, com os dados fornecidos pelo(a) autor(a)

de Freitas Vieira, Heitor
Provendo resiliência em uma rede de sensores sem
fio linear e esparsa através de veículo aéreo não
tripulado / Heitor de Freitas Vieira; orientador Jó
Ueyama. -- São Carlos, 2015.
$56 \mathrm{p.}$
Tese (Doutorado - Programa de Pós-Graduação em
Ciências de Computação e Matemática Computacional) --
Instituto de Ciências Matemáticas e de Computação,
Universidade de São Paulo, 2015.
1. Veículo aéreo não tripulado. 2. Rede de
sensores sem fio. 3. ZigBee. 4. Consumo energético.
5. Mitigação de desastres naturais. I. Ueyama, Jó,
orient. II. Título.


A sua imaginação é o trailer das próximas atrações da vida.

Albert Einstein 

À minha mãe, Maria Assunção, pelo exemplo e perseverança na luta contra o câncer e, acima de tudo, pela alegria de viver. 



\section{Agradecimentos}

Aos meus pais José e Maria, aos meus irmãos Márcia, Jaime e Larissa, e minha sobrinha Alice por insistirem em mim por todos esses anos.

Ao Prof. Dr. Jó Ueyama, pela orientação e pelas oportunidades abertas a mim.

Aos meus amigos Bruno Faiçal, Geraldo Pereira, Gustavo Pessin e Leandro Mano, pelas críticas e sugestões, úteis no enriquecimento da minha formação profissional.

A todos os amigos do Laboratório de Sistemas Distribuídos e Programação Concorrente (LaSDPC) pelas saudosas e divertidas conversas.

Ao Instituto de Ciências Matemáticas e de Computação (ICMC) e todos os seus funcionários, e a Universidade de São Paulo, que contribuíram para minha formação profissional.

Ao Conselho Nacional de Desenvolvimento Científico e Tecnológico (CNPq) pelo apoio financeiro. 



\begin{abstract}
A mitigação de desastres naturais exige respostas rápidas e confiáveis. No Brasil, a estação de chuvas provoca muitos alagamentos em regiões urbanas e, para monitorar esse fenômeno, foi instalada em São Carlos-SP uma rede de sensores sem fio para acompanhar o nível de água dos rios da cidade. Entretanto, essa rede de sensores está suscetível a falhas que podem comprometer o funcionamento do sistema, e a adoção de mecanismos redundantes e de redes móveis $3 \mathrm{G}$ podem acarretar em custos proibitivos à monitoração desses rios, além de não garantirem a operação normal desse monitoramento. Assim, este trabalho apresenta uma solução baseada em veículo aéreo não tripulado (VANT) para reduzir os problemas oriundos das falhas em uma rede de sensores para detectar desastres naturais como enchentes e deslizamentos. Na solução proposta, o VANT pode ser transportado para o sítio do desastre para minimizar os problemas provenientes das falhas (por exemplo, para servir como um roteador ou até mesmo para servir como uma mula de dados e transmitir imagens em tempo real para equipes de resgate). Estudos foram conduzidos em um protótipo real, equipado com o UAV Brain (módulo computacional desenvolvido especificamente para este projeto), para uma análise exploratória do consumo energético do VANT e do rádio transmissor que equipa o VANT. Os resultados mostram que a melhor situação para o rádio comunicador se dá quando o VANT está no ar e com uma antena de maior ganho, e os fatores que mais influenciam no consumo energético do rádio são a altura do VANT e o tipo de antena utilizado. Além disso, tais resultados mostram também a viabilidade desta proposta em redes de sensores sem fio linear e esparsa.
\end{abstract}



he mitigation of natural disasters requires quick and reliable answers. In Brazil, the rainy season causes many flooding in urban areas and, to monitor this phenomenon, a wireless sensor network to monitor the water level of the city's rivers was installed in São Carlos-SP. However, this sensor network is susceptible to failures that may jeopardize the operation of the system, and the adoption of redundant mechanisms and $3 \mathrm{G}$ mobile networks may result in prohibitive costs to the monitoring of these rivers, and does not guarantee the normal operation of monitoring. This work presents an aerial vehicle-based solution unmanned (UAV) to reduce the problems originated from failures in a network of sensors to detect natural disasters such as floods and landslides. In the proposed solution, the UAV can be transported to the disaster site to minimize problems arising from failures (eg, to serve as a router or even to serve as a data mule and transmit images in real time for rescue teams). Studies were conducted in a real prototype, equipped with UAV Brain (computational module developed specifically for this project), for an exploratory analysis of the energy consumption UAV and radio transmitter fitted to the UAV. The results show that the best situation for the radio communicator is when the UAV is in the air and with a higher gain antenna, and the factors that most influence on the radio energy consumption are the height of the UAV and the type of antenna used. Furthermore, these results also show the feasibility of this proposal in linear and sparse wireless sensor networks. 

Resumo

$\begin{array}{lll}\text { Abstract } & \text { iii }\end{array}$

$\begin{array}{ll}\text { Lista de abreviaturas } & \text { ix }\end{array}$

1 Introdução $\quad 1$

1.1 Contextualização e justificativa . . . . . . . . . . . . . . . . . . 1

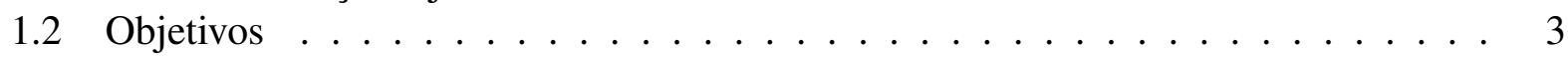

1.3 Estrutura do Trabalho . . . . . . . . . . . . . . . 4

2 Fundamentação teórica $\quad \mathbf{5}$

2.1 Redes de Sensores Sem Fio - RSSF . . . . . . . . . . . . . . . . . . 6

2.1.1 e-NOÉ: Uma RSSF Para Monitoramento de Rios Urbanos . . . . . . . . . 8

2.2 O Rádio Transceptor ZigBee . . . . . . . . . . . . . . . . . . . . . . . 11

2.2.1 Características do ZigBee . . . . . . . . . . . . . . . . . 12

2.2.2 Arquitetura do ZigBee . . . . . . . . . . . . . . . . . . . 14

2.3 Veículo Aéreo Não Tripulado - VANT . . . . . . . . . . . . . . . . . . . 15

2.3.1 O VANT MikroKopter . . . . . . . . . . . . . . . . . . . . 17

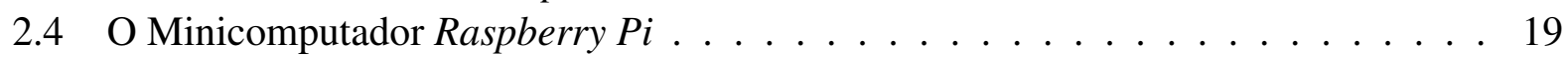

2.5 O Microcontrolador Arduino . . . . . . . . . . . . . . . . . . . . . . . . . . . . . . . . . . . .

2.6 Cálculo do consumo energético . . . . . . . . . . . . . . . 21

3 Trabalhos Relacionados $\quad 23$

3.1 Discussão dos trabalhos relacionados . . . . . . . . . . . . . . . . . . . 25

4 Provendo Resiliência a uma RSSF através de VANT 27

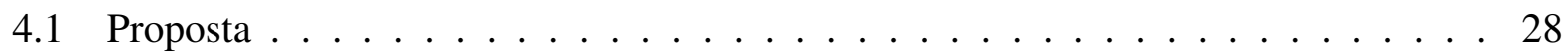

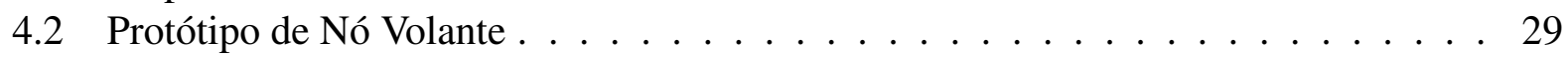

4.2.1 UAV Brain - O módulo computacional do VANT . . . . . . . . . . . . . . . . 30

4.3 Ambiente de experimentação . . . . . . . . . . . . . . . . . . . 31

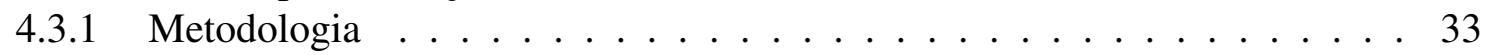

5 Resultados $\quad 37$

5.1 Consumo energético do ZigBee . . . . . . . . . . . . . . . . . . 37

5.2 Round-Trip delay Time $(\mathrm{RTT})$. . . . . . . . . . . . . . . . . . 39 
5.3 Perda de Pacotes . . . . . . . . . . . . . . . . . . . . . . . . 39

5.4 Consumo Energético do VANT . . . . . . . . . . . . . . . . . . . 41

5.5 Transmissão de Imagens . . . . . . . . . . . . . . . . . . . . . . . . . . . . . . . . . . . . . .

5.6 Discussão dos Resultados . . . . . . . . . . . . . . . . . . . . 42

6 Considerações Finais $\quad \mathbf{4 5}$

6.1 Principais contribuições deste trabalho . . . . . . . . . . . . . . . . . 46

6.2 Trabalhos Futuros . . . . . . . . . . . . . . . . . . . 47

6.3 Produção Acadêmica . . . . . . . . . . . . . . . . . . . . . . 48

6.3.1 Exploiting the use of unmanned aerial vehicles to provide resilience in wireless sensor networks - Journal Qualis A1 . . . . . . . . . . . . . . 48

6.3.2 GuideMe Project-Simpósio . . . . . . . . . . . . . . . . . . . . 48

6.3.3 The use of unmanned aerial vehicles and wireless sensor networks for spraying pesticides - Journal Qualis B1 . . . . . . . . . . . . . . . . . 49

6.3.4 A Study Case of Restful Frameworks in Raspberry Pi: A Performance and Energy Overview - Conferência Qualis A1 . . . . . . . . . . . . . . . . . 49

6.3.5 Performance and Energy Evaluation of RESTful Web Services in Raspberry Pi-Conferência Qualis B1 . . . . . . . . . . . . . . 50 


\section{Lista de Figuras}

1.1 Modos de operação da RSSF . . . . . . . . . . . . . . . . . . . . 3

2.1 Arquitetura de uma RSSF . . . . . . . . . . . . . . . . . . . 6

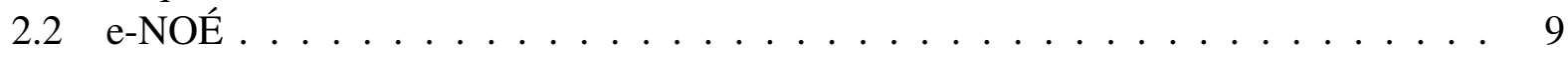

2.3 Detalhes de um nó sensor do e-NOÉ . . . . . . . . . . . . . . . . . . . 9

2.4 Serviço web do e-NOÉ . . . . . . . . . . . . . . . . . . . . 11

2.5 Uma possível rede ZigBee . . . . . . . . . . . . . . . . . . . . . . 12

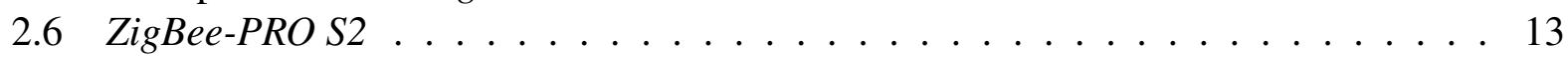

2.7 Redes mesh ZigBee . . . . . . . . . . . . . . . . . . . . . . . . . . . . 14

2.8 Arquitetura do ZigBee . . . . . . . . . . . . . . . . . . . 15

2.9 O VANT MikroKopter Okto . . . . . . . . . . . . . . . . . . . . . . . . . 17

2.10 Componentes do MikroKopter Okto _ . . . . . . . . . . . . . . . . . . . 18

2.11 Raspberry Pi Modelo B . . . . . . . . . . . . . . . . . . . . . . 20

2.12 Arduino nano V3.0 . . . . . . . . . . . . . . . . . . . 20

2.13 Arduino shield . . . . . . . . . . . . . . . . . . . 21

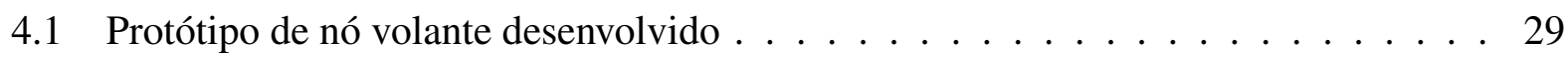

4.2 UAV Brain . . . . . . . . . . . . . . . . . . . . . . . 30

4.3 Arquitetura de hardware do UAV Brain . . . . . . . . . . . . . . . . . 31

4.4 Power meter shield . . . . . . . . . . . . . . . . . . . . . . . . 31

4.5 Cenário dos experimentos . . . . . . . . . . . . . . . . . . . . . . . . . . . . . . . . .

4.6 Diagrama de atividades do cliente . . . . . . . . . . . . . . . . 34

4.7 Diagrama de atividades do Raspberry Pi embarcado no nó volante . . . . . . . . . 35

4.8 Diagrama de atividades do Arduino embarcado no nó volante . . . . . . . . . . . 36

4.9 Diagrama de atividades do servidor . . . . . . . . . . . . . . . . 36

5.1 Resultados do consumo energético do ZigBee . . . . . . . . . . . . . . . 38

5.2 Interação entre os fatores no consumo energético do ZigBee . . . . . . . . . . . . 38

5.3 Influência dos fatores no consumo energético do ZigBee . . . . . . . . . . . . . . 39

5.4 Resultados do RTT . . . . . . . . . . . . . . . . . . . . . . . 40

5.5 Interação entre os fatores no RTT . . . . . . . . . . . . . . . . . . . . . . . . . . . . . . . . . . .

5.6 Consumo energético do VANT . . . . . . . . . . . . . . . . . . . . . . . . . . . . . . .

5.7 Protótipo de nó volante desenvolvido . . . . . . . . . . . . . . . . . 43

5.8 Imagens capturadas em voo . . . . . . . . . . . . . . . . . . . . . . . 44 



\section{Lista de Tabelas}

2.1 Características Raspberry Pi (Modelo B - rev 2) . . . . . . . . . . . . . . . . . . . 19

3.1 Resumo das principais características dos trabalhos relacionados . . . . . . . . 25

4.1 Conjunto de fatores primários avaliados . . . . . . . . . . . . . 33

4.2 Fatores secundários presentes no experimento . . . . . . . . . . . 33

$5.1 \quad$ Resultados do RTT . . . . . . . . . . . . . . . . . . . 41 



\section{Lista de Abreviaturas}

ANAC Agência Nacional de Aviação Civil

AODV Ad Hoc On-Demand Vector Routing

API Application Programming Interface

CDMA Code Division Multiple Access

CPU Central Processing Unit

CSMA-CA Carrier sense multiple access with collision avoidance

DIN Data In

DOUT Data Out

DSP Digital Signal Processor

DSSS Direct-Sequence Spread Spectrum

EDGE Enhanced Data rates for GSM Evolution

$\mathrm{GHz}$ Giga Hertz

GNU GNU is Not Unix

GPIO General-Purpose Input/Output

GPS Global Positioning System

GPU Graphics Processing Unit

GSM Groupe Spécial Mobile

HDMI High-Definition Multimedia Interface

HSPA High Speed Packet Access

IEEE Institute of Electrical and Electronics Engineers

IMU Inertial Measurement Unit 
LCD Liquid-Crystal Display

LED Light-Emitting Diode

LGPL GNU Lesser General Public License

MAC Media Access Control

MB Mega Bytes

$\mathrm{MHz}$ Mega Hertz

MIMO Multiple Input Multiple Output

NS Nó Sensor

NTSC National Television Comittee

O-QPSK Offset Quadrature Phase-Shift Keying

OS Operational System

OSI Open System Interconnection

PAL Phase Alternating Line

PAN Personal Area Network

PC Personal Computer

PER Packet Error Rate

PWM Pulse With Modulation

RAM Random-Access Memory

ROS Robot Operating System

RSSI Received Signal Strength Indicator

RTCC Real Time Clock and Calendar

RTT Round-Trip delay Time

SD Secure Digital

SI Sistema Internacional de Unidades

SO Sistema Operacional

SPI Serial Peripheral Interface

SRAM Static Random-Access Memory

TSP Traveling Salesman Problem

UART Universal Asynchronous Receiver/Transmitter 
UAV Unmanned Aerial Vehicle

USB Universal Serial Bus

VANT Veículo Aéreo Não Tripulado

WAVE wireless access in vehicular environments 
Uma rede de sensores sem fio (sistema distribuído constituído por sensores interligados por um canal de comunicação sem fio) pode monitorar adequadamente o nível de rios e gerar alertas, por exemplo. Com esse propósito, foi instalada na cidade de São Carlos-SP uma rede de sensores sem fio para o monitoramento de seus rios urbanos. Entretanto, em desastres naturais esses sensores podem ser danificados, e esse fato pode comprometer o funcionamento do sistema. A adoção de mecanismos de redundância pode aumentar o tempo de vida da rede, mas não garante seu o funcionamento. Uma solução viável é a utilização de veículos aéreos não tripulados para prover resiliência ${ }^{1}$ a uma rede de sensores sem fio, pois podem trafegar em locais inacessíveis a outros tipos de veículos (terrestres e marítimos), e podem desempenhar um papel decisivo no resgate de vítimas.

\subsection{Contextualização e justificativa}

Embora muitos desastres naturais não possam ser evitados, seus efeitos podem ser atenuados através da emissão de alertas prévios e procedimentos de resgate apropriados. Após a catástrofe, o monitoramento da região atingida é de vital importância para que se possa mensurar os estragos de forma precisa e, com isso, elaborar estratégias de resgate eficientes com a propensão de preservar vidas humanas. Uma rede de sensores sem fio (RSSF) pode ser uma solução tecnológica viável para o monitoramento de rios urbanos, por exemplo.

\footnotetext{
${ }^{1}$ Capacidade de um sistema restabelecer seu equilíbrio após este ter sido rompido por um distúrbio. Difere de resistência, que é a capacidade de um sistema de manter sua estrutura e funcionamento após um distúrbio.
} 
De forma sucinta, uma RSSF é um sistema distribuído e constituído por sensores interligados por um canal de comunicação sem fio. Esses sensores são normalmente utilizados para o monitoramento de fenômenos físicos como temperatura, pressão atmosférica e luz, por diversos propósitos, como médico, civil e militar. A comunicação desses sensores se dá através de multi saltos, ou multi-hops em Inglês, desse modo um sensor se comunica com seu vizinho até que a mensagem chegue ao destino final, normalmente um nó sink.

A RSSF e-NOÉ (Hughes et al., 2011), que monitora a atividade de rios urbanos na cidade de São Carlos-SP, gera alertas para moradores ribeirinhos e veículos que trafegam por locais em situação de risco, com o objetivo de evitar, ou ao menos minimizar, danos e prejuízos aos moradores e frequentadores do entorno desses rios. Até o presente momento, a rede e-NOÉ possui oito nós sensores.

Rios urbanos normalmente são cercados por ruas e avenidas de grande porte, como a Marginal Tietê em São Paulo. Em São Carlos há a Marginal Tijuco Preto. Uma consequência inerente a essa situação é a de que essas vias estão sujeitas a inundações e essas circunstâncias exigem cuidados especiais, os quais inclui envio de alertas a motoristas, para que evitem trafegar pela região, e a moradores, para que tomem medidas de defesa patrimonial ou para que saiam de suas casas a tempo.

Os rios urbanos da cidade de São Carlos são mais retilíneos e menos sinuosos, portanto, a topologia da rede instalada nesses rios é linear e esparsa. Como os sensores estão dispostos em uma rede de topologia linear, a RSSF e-NOÉ utiliza o comunicador sem fio ZigBee em modo multi salto. Deste modo, torna-se claro que a falha de um único nó pode comprometer o funcionamento parcial ou total dessa RSSF.

Para evitar essa situação, idealizam-se alguns mecanismos de tolerância a falhas para a e-NOÉ, como o uso de comunicação através da terceira geração $(3 \mathrm{G})$ de telefonia móvel em caso de falha na comunicação multi salto, a adoção de nós extras e a replicação de componentes internos de um nó sensor. Por questões de custos, nem todos os nós sensores da e-NOÉ estão equipados com tecnologia $3 \mathrm{G}$ e componentes extras. Nesse cenário, esses nós sensores com modem $3 \mathrm{G}$ podem ser destruídos e/ou a rede $3 \mathrm{G}$ pode ficar inoperante por qualquer motivo durante o período crítico de enchente.

Uma solução para essa situação é o uso de veículos aéreos não tripulados (VANTs) para tornar a RSSF mais resiliente em momentos de falhas durante desastres naturais, os quais a e-NOÉ está passível a sofrer. VANTs são utilizados para diversos fins, incluindo tarefas civis ou militares, como vigilância, monitoramento e mapeamento aéreo. Uma outra utilização de VANT(s) pode ser para manter a conectividade de uma rede sem fio em caso de falhas em sua infraestrutura.

Na proposta aqui apresentada, um microcóptero (um mini VANT) pode ser empregado com três características:

i Servir como um roteador em caso de falha de um nó numa comunicação multi salto (ver Figura 1.1); 
ii Para atuar como mula de dados (Tekdas et al., 2009) para disseminação de dados, o que pode auxiliar na formação de uma rede tolerante a atrasos (em Inglês Delay Tolerant Network DTN) na qual os pacotes da RSSF podem ser divulgados em uma rede veicular (VANET) para que os motoristas possam evitar vias inundadas.

iii Através de uma câmera instalada no VANT, pode-se transmitir imagens em tempo real para equipes de resgate;

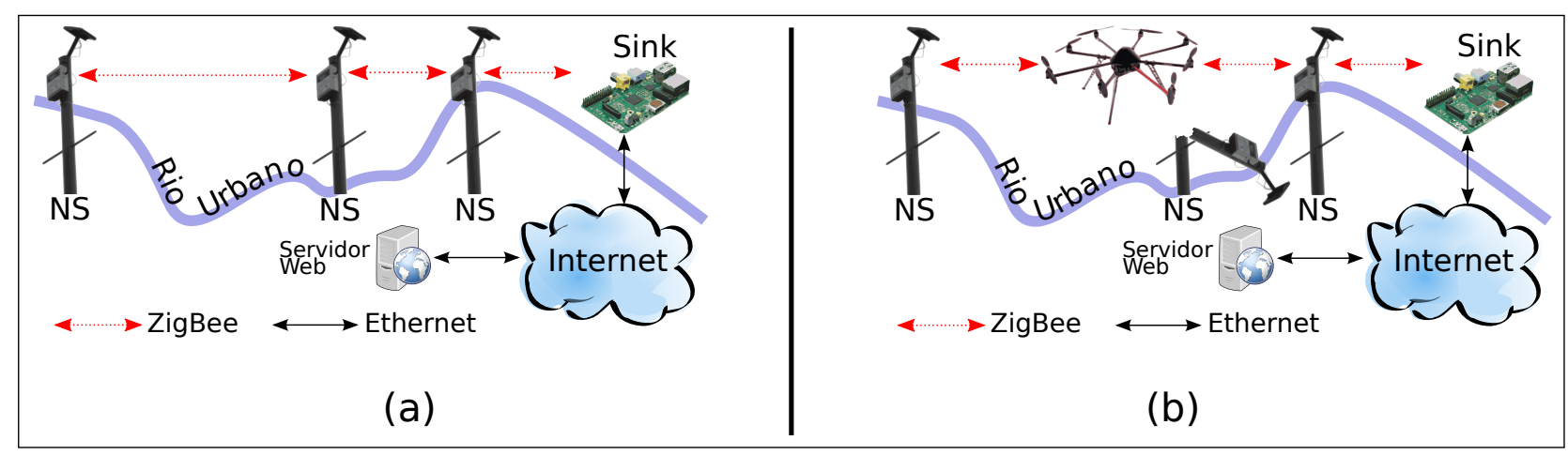

Figura 1.1: Quando a RSSF está em funcionamento normal, a mensagem com informações sobre as atividades do rio urbano são transmitidas através de multi saltos até que cheguem ao nó Sink: a) O nó Sink envia através da Internet as informações de todos os nós para uma central de processamento (Servidor Web). b) Quando uma falha ocorre em um nó sensor, o nó antecessor não consegue transmitir seus dados até o nó Sink. Uma vez que esse trecho da rede fique inoperante (sem comunicação), a RSSF ficará inoperante até que o nó falho seja reparado ou substituído. Com a utilização de um nó volante é possível reestabelecer a comunicação da RSSF ou coletar os dados e transmiti-los para a central de processamento. Essa escolha é feita de acordo com o plano de ação a ser utilizado.

Para provar a viabilidade desta proposta, conduziu-se um estudo analítico sobre a comunicação sem fio entre dois sensores em terra e um VANT, aqui chamado de nó volante. A característicachave das análises é uma avaliação do consumo energético do dispositivo de comunicação sem fio, o qual é embarcado no nó volante (VANT), no tempo de resposta da rede, nas perdas de pacotes e no consumo energético do nó volante (VANT).

\subsection{Objetivos}

Este trabalho investiga como um nó volante pode ser capaz de prover resiliência a uma RSSF empregada para monitorar rios urbanos. A RSSF coleta informações sobre o comportamento do rio e transmite esses dados para uma central de processamento, onde esses dados são utilizados para prever situações futuras, incluindo possíveis alagamentos, do rio analisado.

Para isso, foi construído um protótipo real e conduzida uma análise exploratória do consumo energético do VANT e do rádio transmissor (sem a ajuda de ferramentas de simulação). Um nó sensor, acoplado a um VANT, é capaz de comunicar-se com a RSSF instalada na área de interesse (nas margens de um rio urbano), tornando-se, assim, um nó volante. 


\subsection{Estrutura do Trabalho}

O restante desta dissertação está organizado da seguinte forma. No Capítulo 2, é feita uma fundamentação teórica relacionada ao projeto de pesquisa, visando a oferecer a base teórica necessária para a compreensão do assunto abordado no Capítulo 3. No Capítulo 4, é discutida a visão geral do projeto, bem como suas potencialidades e limitações. Além disso, são mostrados a plataforma construída, o método proposto e os critérios de avaliação. No Capítulo 5, são apresentados os resultados alcançados. Finalmente, o Capítulo 6 traz as considerações finais e as contribuições deste trabalho. 


\section{Fundamentação teórica}

Rede de sensores sem fio é uma rede composta por múltiplos nós sensores imersos em uma região em que se deseja monitorar alguma atividade ou fenômeno. Suas aplicações são inúmeras e vão desde monitoramento de vulcões até a observação de enfermos. Dentre as aplicações dessa rede, detacam-se as ambientais, como o monitoramento de rios urbanos para geração de alertas para a população ribeirinha. Devido a isso, utilizou-se a rede de sensores sem fio e-NOÉ, para monitoramento de rios urbanos, como estudo de caso para a validação da proposta deste trabalho; Um módulo de rádio bastante utilizado nessas redes é o ZigBee, por transmitir dados com baixo consumo de energia elétrica por longas distâncias; Veículos aéreos não tripulados são aeronaves projetadas para operar sem piloto abordo e pertencem a duas categorias, de asa fixa ou rotativa. Suas aplicações vão desde missões militares, como vigilância de fronteiras a entrega de encomendas. Estima-se que o mercado dessas aeronaves irá movimentar a soma de US\$91 bilhões nos próximos dez anos; Raspberry Pi é um minicomputador de baixo custo, pequeno porte computacional, dimensões físicas reduzidas, baixo consumo energético, se comparado a um PC comum, e capaz de executar um sistema operacional baseado em Linux. Neste projeto, o Raspberry Pi foi utilizado como agente computacional, embarcado num veículo aéreo não tripulado, para processar dados e informações relativos à comunicação e aquisição de dados de consumos energéticos; Arduino é uma placa de controle para entrada e saída de dados. Utilizou-se o Arduino, neste projeto, como agente de tempo real responsável pela aquisição de dados de sensores alojados na aeronave. A união de veículo aéreo não tripulado, Raspberry Pi, Arduino e outros componentes adicionais formou um nó volante capaz de interligar nós sensores em uma rede de sensores sem fio. 


\subsection{Redes de Sensores Sem Fio - RSSF}

Uma Rede de Sensores Sem Fio (RSSF) é formada por múltiplos Nós Sensores (NS), que podem estar dispostos perto e/ou dentro de fenômenos que se desejam monitorar (e.g., temperatura e luminosidade) (Akyildiz e Vuran, 2010). A localização dos nós pode ou não ser pré-determinada. Essas características tornam esses sensores ideais para a instalação em ambientes inacessíveis, ou de difícil acesso para seres humanos, (tais como nas áreas militares, industriais, aviação, ambientais, de engenharia, etc.), podendo, inclusive, ser distribuídos por veículos aéreos não tripulados, como descreve o artigo (Erman et al., 2008).

A arquitetura de RSSF mais presente na literatura (Akyildiz e Vuran, 2010) é ilustrada pela Figura 2.1. Costumeiramente, são utilizados dois tipos de dispositivos, um com menor capacidade computacional, e portanto menos dispendioso, alocado em grande quantidade dentro da região de interesse para que se possa monitorar adequadamente ${ }^{1}$ um fenômeno físico/químico. A esse dispositivo emprega-se o nome de nó sensor. O outro tipo de dispositivo é chamado de nó Sink, o qual possui maior capacidade computacional e também a função primária de realizar a ponte entre a RSSF e o mundo exterior, um nó para gerenciamento de tarefa, que normalmente utiliza protocolos nativos à Internet (Wi-Fi (IEEE, 2014a) ou Ethernet (IEEE, 2014b)).

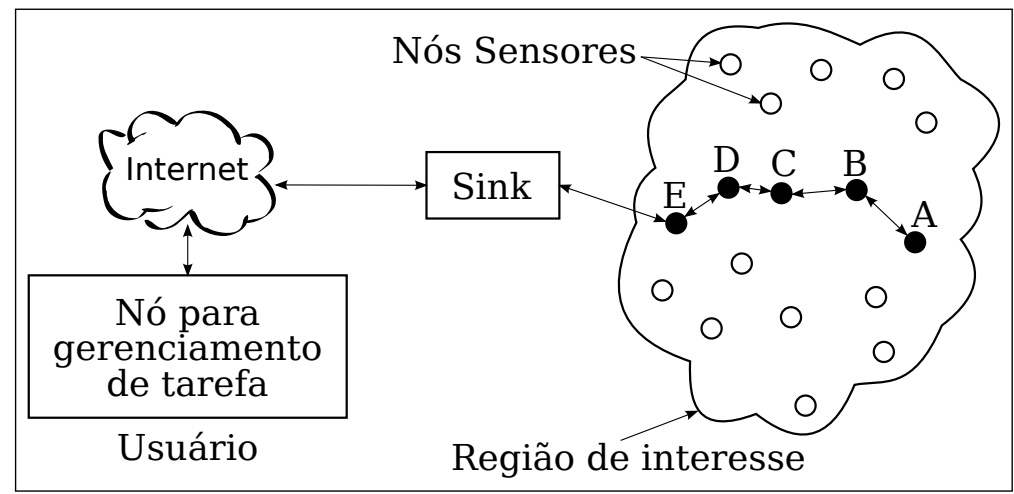

Figura 2.1: Arquitetura de uma RSSF: Composta por nós sensores, localizados em uma área de interesse para o monitoramento de fenômeno(s) e que se comunicam através de multi saltos, e um nó Sink, responsável pelo intermédio entre redes diferentes. Adaptado de (Akyildiz e Vuran, 2010)

Cada nó sensor é capaz de (i) adquirir dados, através de sensoriamento, e processá-los, podendo detectar eventos ${ }^{2}$, (ii) comunicar esses eventos a seus vizinhos através de um rádio e (iii) auxiliar na propagação de dados/informações de seus vizinhos, para que o evento seja entregue a um sorvedouro, ou nó Sink. Esses nós sensores também podem operar como network relays ${ }^{3}$.

Um nó sensor é composto por três componentes (Akyildiz e Vuran, 2010):

\footnotetext{
${ }^{1}$ Uma RSSF pode monitorar a propagação de um gás em um ambiente ao invés de simplesmente detectar a presença do gás.

${ }^{2}$ Os quais podem ser incêndio, inundação, entre outros.

${ }^{3}$ Repetidores em uma rede sem fio para transmitir dados para o destinatário fora da área de cobertura.
} 
1. Módulo sem fio ou mote: é o principal componente dos nós sensores por possuir capacidade de comunicação e programação. Habitualmente, um mote é composto por um microcontrolador, um rádio para comunicação, fonte de alimentação e memória. Alguns motes podem dispor de sensores, como sensor de temperatura, pressão, umidade, luminosidade, entre outros;

2. Conjunto de sensores: para capturar dados do ambiente em que estão inseridos e podem ser acoplados aos motes com o intuito de aumentar suas capacidades sensitivas;

3. Placa de dados: interfaces como Ethernet, USB ou portas seriais que são utilizadas para conectar os motes a computadores para programação ou transmissão de dados. Alguns modelos de motes permitem essa programação por meio da comunicação sem fio.

A principal limitação dos nós sensores é sua fonte de alimentação que normalmente são pequenas baterias, portanto com baixa capacidade de armazenamento de carga. Essa característica traz a inconveniente necessidade de substituição periódica dessas baterias, uma vez que esses nós sensores podem estar em locais inacessíveis, dificultando a substituição de suas baterias. No entanto, em alguns casos, é possível atenuar essa limitação através de alimentação fornecida por painel solar. Por esses motivos, o maior desafio de uma RSSF é a conservação da energia disponível nos nós sensores com o objetivo de prolongar o tempo de vida da rede (Akyildiz et al., 2002).

Segundo uma análise (Niculescu, 2005) do consumo energético de um nó sensor específico, o componente que mais consome energia em um nó sensor é seu rádio. Para transmitir 100 bits de dados por 100 metros foram gastos $10 \mu \mathrm{J}$, enquanto que para cada instrução de 32 bits são necessários $0.06 \eta \mathrm{J}$, ou seja, para enviar 100 bits por 100 metros gasta-se 100.000 vezes mais energia do que processar uma instrução de 32 bits. Por esse motivo, para economizar energia, os nós sensores comprimem e agregam dados antes de transmiti-los, além de utilizarem rádios de curta distância.

Os sinais sobre diferentes meios comportam-se de formas distintas, dependendo das propriedades físicas do respectivo meio de propagação. Os sinais estão sujeitos à atenuação e a diferentes tipos de ruídos, os quais estão presentes em todos os meios em diferentes intensidades. Porém, existem grandes diferenças entre meios de comunicação com e sem fio. No fio, os sinais são sempre transmitidos através de um meio sólido ou guiado, como o par trançado, e, portanto, eles são em grande parte protegidos de ruídos provenientes de fora do meio de transmissão.

As comunicações sem fio, por outro lado, baseiam-se em meios não guiados como a atmosfera, espaço ou água, e assim os sinais podem estar expostos às várias fontes de interferência em sua transmissão desde o emissor até o receptor. Além disso, a maneira como os sinais se propagam também depende do seu espectro (Kupper, 2005). Portanto, a utilização de comunicação sem fio, ou mesmo de rádio de curto alcance, pode ocasionar em falhas de comunicação e, com isso, os nós sensores não conseguem transmitir seus dados até o nó Sink. 
Outra modificação ocasionada pela restrição de energia dos nós é a redução do ciclo de trabalho. Para realizar um baixo consumo de energia, os nós periodicamente ligam e desligam vários componentes, como os seus sensores e o rádio. No entanto, esse comportamento causa indisponibilidade temporária no acesso aos nós sensores. Assim, os algoritmos e protocolos de rede de uma RSSF precisam tratar esse tipo de comportamento. Um exemplo de desperdício de energia no uso de protocolos tradicionais em uma RSSF é dado por (Halkes et al., 2005), texto em que é demonstrado o uso do protocolo IEEE802.11 (IEEE, 2014a) por um nó de sensor, transmitindo mensagens à taxa de uma mensagem por segundo.

O estado da arte em nós de sensores sem fio é mostrado em (Warneke et al., 2001), trabalho em que é proposto o desenvolvimento de um nó de sensor de um milímetro cúbico. Há diversas pesquisas que empregam RSSFs (Ueyama et al., 2010; Villas, 2012; Erol-Kantarci e Mouftah, 2011; Kim et al., 2008; Juang et al., 2002; Sibbald, 2001). Na área médica, destaca-se a utilização em dispositivos biomédicos (Malan et al., 2004; Akyildiz et al., 2002; Sibbald, 2001), monitoramento de sinais vitais de pacientes (Malan et al., 2004), rastreamento de pacientes (Akyildiz et al., 2002). $\mathrm{Na}$ área ambiental, destaca-se o sistema de detecção de inundação (Basha et al., 2008), (Lorincz et al., 2006) mostra a viabilidade das RSSFs para monitoramento de vulcões e o monitoramento de animais selvagens (Juang et al., 2002). Dentre as aplicações ambientais, destacam-se os estudos para monitoramento de rios urbanos com objetivo de antever inundações (Hughes, 2008; Ueyama et al., 2010). Em especial, evidencia-se a RSSF e-NOÉ para o monitoramento de rios urbanos, que é melhor descrita na seção subsequente.

\subsection{1 e-NOÉ: Uma RSSF Para Monitoramento de Rios Urbanos}

e-NOÉ (Hughes et al., 2011) é um projeto brasileiro para monitoramento de rios urbanos liderado pelo Instituto de Ciências Matemáticas e de Computação (ICMC) da Universidade de São Paulo (USP) e conta com a parceria de hidrólogos da Escola de Engenharia de São Carlos (EESC) também da USP. Um dos propósitos desse projeto é prover condições de monitoramento de rios urbanos a fim de gerar alertas e evitar danos maiores, como perdas de vidas.

O componente de sensoriamento do projeto e-NOÉ, também chamado de nó sensor, é dotado de sensores (e.g., pressão, temperatura, entre outros), que estão instalados em pontos estrategicamente escolhidos por hidrólogos ao longo das margens de rios na cidade de São Carlos-SP, estando conectados entre si através de um link sem fio. Os nós sensores comunicam-se entre si a fim de estabelecer uma ligação com a estação base, responsável pela conversão das redes ZigBee-Ethernet.

Para a realização deste trabalho, a rede e-NOÉ utiliza um sensor de pressão, pois pelos princípios físicos, a pressão exercida em determinado ponto dentro do rio é devido à altura da coluna de água acima desse ponto. Sendo assim, com um sensor de pressão obtém-se facilmente a altura da coluna de água acima dele. Se essa altura aumentar abruptamente em um pequeno intervalo de tempo, isso pode significar indícios de uma possível enchente; alertas podem ser enviados à popu- 
lação que se encontra em áreas de risco. Veja uma visão geral de seu funcionamento na Figura 2.2 e detalhes do nó sensor na Figura 2.3.

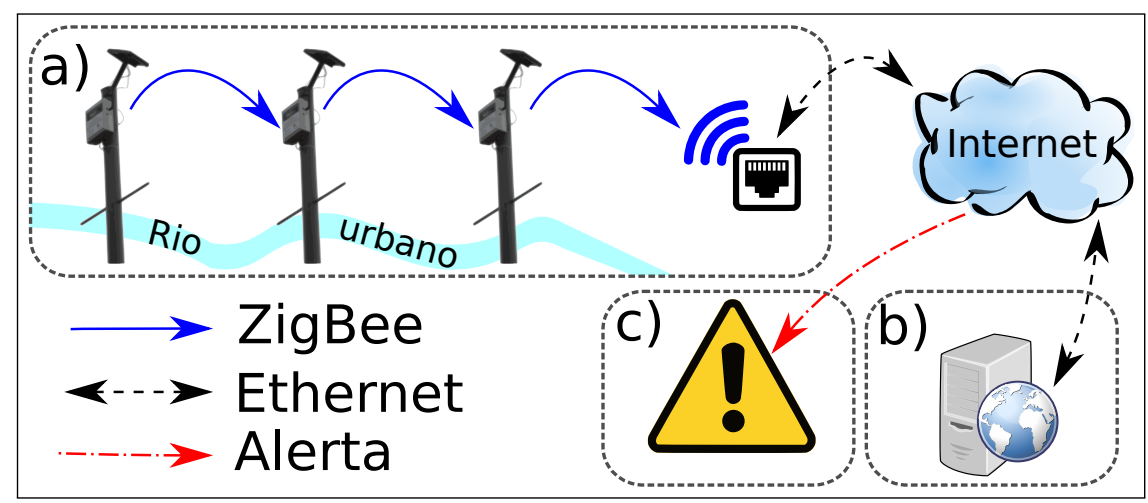

Figura 2.2: Arquitetura da RSSF e-NOÉ: a) Transmissão via multi saltos de dados coletados do rio pelos Nós Sensores até a estação base; b) Armazenamento de dados e predição de inundações; c) Geração de alertas para a população ribeirinha.

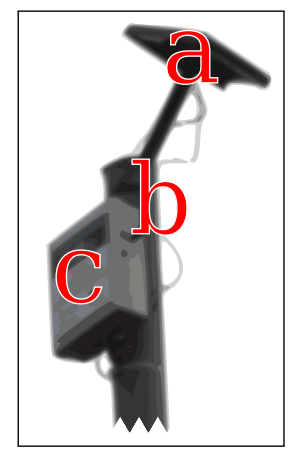

Figura 2.3: Detalhes de um nó sensor do e-NOÉ: a) Painel solar; b) Antena para transmissão de dados sem fio; c) Caixa com circuitos eletrônicos composta basicamente por microcontrolador, bateria, sensor de temperatura e rádio ZigBee.

As transmissões de pacotes com dados são feitas a cada cinco minutos, valor este determinado por hidrólogos. Como cada nó sensor possui um registro de identificação, é possível determinar qual nó sensor deixou de transmitir suas informações, portanto o nó sensor defeituoso. Como os nós sensores possuem localização fixa e conhecida, através da determinação do nó sensor defeituoso pode-se tomar as decisões apropriadas para reparo da rede.

Algumas possíveis falhas que podem ocorrer nos nós sensores são discutidas abaixo:

\section{Bateria com pouca carga ou defeituosa}

A bateria do nó sensor pode ser precariamente recarregada devido às características do verão brasileiro, muito chuvoso e nublado e, portanto, nesse cenário, torna-se muito difícil de ser feitos a previsibilidade da duração da bateria. No entanto, é justamente na época das chuvas que se precisa de maior confiabilidade, dado maiores probabilidades de chuvas torrenciais e inundações. 


\section{Falha do painel solar}

O painel solar possui prazo de validade e, varia muito de acordo com as condições ambientais em que ele está inserido. Essas condições podem ser altas temperaturas, alta umidade do ar e sujeira excessiva.

\section{Falha de algum outro componente}

Por ser instalado em um poste metálico, o nó sensor está sujeito a avarias provocadas por raios, por exemplo. O microcontrolador e o rádio ZigBee podem parar de funcionar devido às características hostis para equipamentos eletrônicos, como altas temperaturas e elevada umidade do ar.

De forma resumida, as principais características da RSSF e-NOÉ são:

\section{Características da rede :}

- Linear;

- Esparsa;

- Possui atualmente oito nós sensores;

- DTN (Delay Tolerant Network) (Burleigh et al., 2003), ou rede tolerante a atrasos;

- Comunicação através de multi salto (multi-hop).

\section{Características do nó sensor :}

- Rádio transceptor ZigBee (modelo S2-pro de 2,4GHz);

- Alimentado por painel solar;

- Utiliza bateria;

- Medidor de profundidade do rio;

- Sensor de temperatura.

\section{Outras características :}

- Instalada na cidade de São Carlos-SP;

- Possui pluviômetro;

- O nó sensor próximo ao Shopping Iguatemi é isolado da rede ZigBee e possui câmera acoplada a um modem $3 \mathrm{G}$.

A Figura 2.4 mostra a interface web ${ }^{4}$ do projeto e-NOÉ, no qual a população pode ter acesso a dados sobre o rio Monjolinho na cidade de São Carlos-SP.

\footnotetext{
${ }^{4}$ http: //www.agora.icmc.usp.br: $8080 /$ AgoraSADEv2
} 


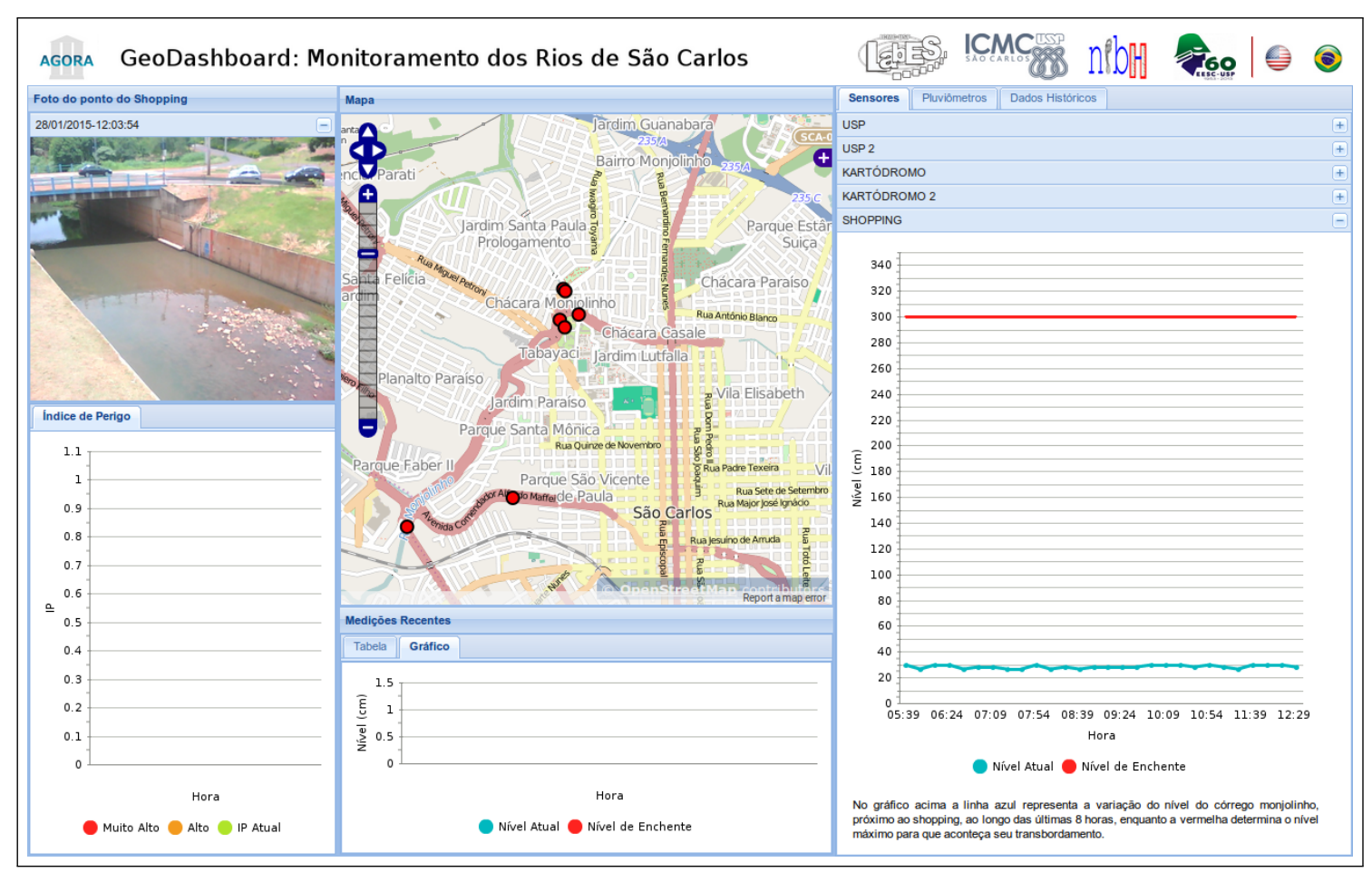

Figura 2.4: Serviço web do e-NOÉ: Interface web do e-NOÉ. Fonte: (e-NOÉ, 2015).

\subsection{O Rádio Transceptor ZigBee}

A RSSF e-NOÉ utiliza esse módulo de rádio para comunicação entre os nós sensores. ZigBee (SENA, 2011) é uma especificação para um conjunto de protocolos de comunicação de alto nível usando pequenos rádios digitais, de baixa potência, baseados no padrão IEEE802 para redes pessoais, Personal Area Network (PAN). O ZigBee é destinado a aplicações que requerem baixa taxa de transferência de dados, longa durabilidade de bateria e redes seguras. Sua taxa de transmissão de dados sem fio é fixa em 250 kbps.

Uma rede ZigBee utiliza comumente a topologia $m a s h^{5}$ e possui três atores (Gascón, 2008): coordenador, roteador e dispositivo final. Um exemplo de rede ZigBee pode ser visto na Figura 2.5. Em cada rede deve haver exatamente um coordenador, dispositivo com maior capacidade computacional responsável por armazenar informações da rede, como repositório para chaves de criptografia, entre outros. O coordenador é a raiz da árvore de rede e serve de ponte para outras sub-redes.

O roteador pode atuar como um roteador intermediário, repassando dados de outros dispositivos. Já o dispositivo final se comunica somente com um nó pai, que pode ser um roteador ou um coordenador. Ele não pode transmitir dados de outros dispositivos e isso permite que o dispositivo final possa dormir em boa parte do tempo, economizando bateria.

Um ZigBee possui três modos de comunicação(Hekkers, 2009): transparente, de comando e Application Programming Interface (API). Ao iniciar, um módulo ZigBee entra em modo transparente. Nesse modo, o módulo atua como uma porta serial. Todos os dados recebidos no pino Data

\footnotetext{
${ }^{5}$ Detalhado pelo item 4 na página 13 e exemplificado pela Figura 2.7 na página 14.
} 


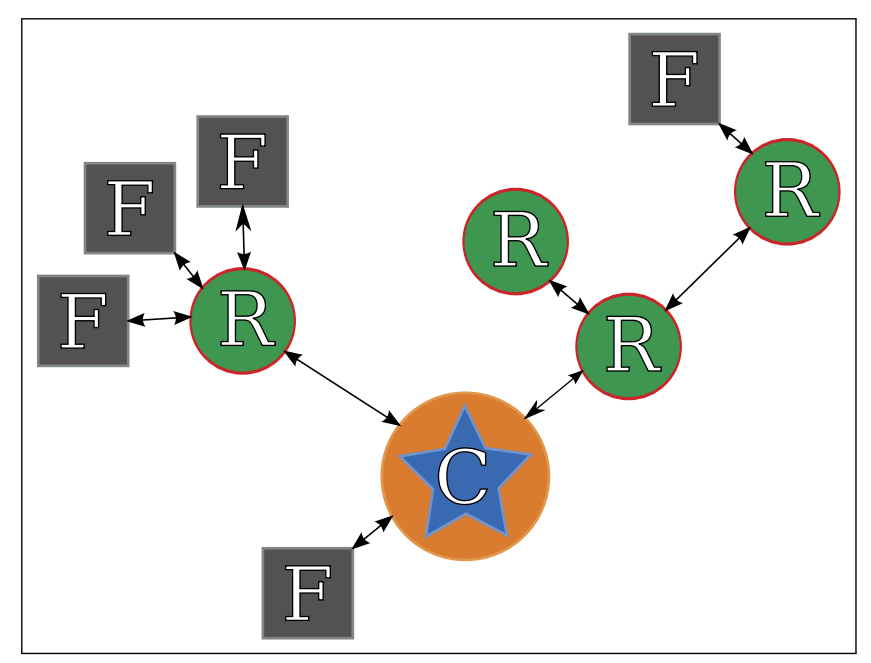

Figura 2.5: Uma possível rede ZigBee: A rede deve possuir somente um coordenador (destacado pela letra $C$ ), pode possuir diversos roteadores (destacado pela letra $R$ ) e pode possuir diversos dispositivos finais (destacado pela letra $F$ ). As setas representam a comunicação sem fio.

In (DIN) são transmitidos e, quando houver dados recebidos por rádio, eles serão enviados para o pino Data Out (DOUT). Um par de ZigBees atua como cabos invisíveis nesse modo. No modo comando pode-se alterar uma grande quantidade de configurações do módulo ZigBee, como taxa de transmissão serial, endereço de destino, entre outros.

O modo API possibilita mais opções e ajustes, no entanto é mais complexo. Ele é baseado em frames para envio e recebimento de dados nas transmissões entre ZigBees. O modo API possui algumas habilidades especiais:

- Possibilidade de mudança de parâmetros sem entrar no modo comando;

- Informações sobre Received Signal Strength Indicator (RSSI) e endereço de origem;

- Confirmação de envio de pacote a cada transmissão.

O modo utilizado neste trabalho é o modo API, por possibilitar o endereçamento diretamente no pacote de dados a ser enviado. Uma foto do módulo ZigBee utilizado neste projeto pode ser visto na Figura 2.6.

\subsubsection{Características do ZigBee}

A especificação ZigBee foi desenvolvida pela aliança ZigBee composta por 250 companhias de todos os continentes (exceto Antártida). ZigBee reside sobre transceptores IEEE 802.15.4, que comunicam na banda de $2.4 \mathrm{GHz}$ a uma taxa de 250 kilobits por segundo (kbps), mas pelas tentativas de transmissão, a encriptação/decriptação e os reconhecimentos da rede mesh, o throughput é próximo a $25 \mathrm{kbps}$. Os transceptores são half duplex, o que significa que eles podem transmitir e receber, mas não ao mesmo tempo, esse é outro fator que reduz a taxa. É esperado que os rádios compartilhem canais, talvez com outras redes ZigBee ou outras tecnologias sem fio. As redes 


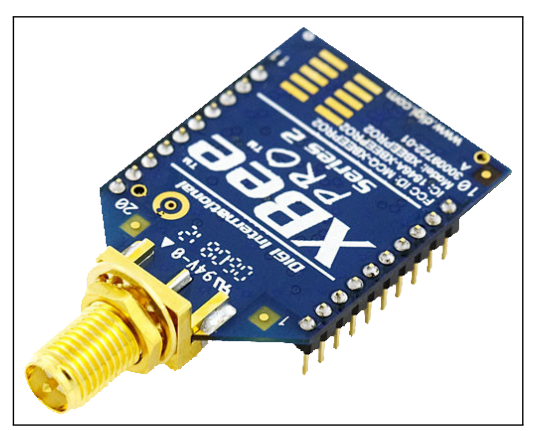

Figura 2.6: Aspecto físico do ZigBee-PRO S2: Rádio transceptor de baixo consumo energético, possui conector RPSMA (para ligação com antena) e DIL (para conexão com circuito eletrônico).

ZigBee têm até 16 canais no espaço de 2,4 GHz, separados por $5 \mathrm{MHz}$ cada um. Cada canal é fisicamente separado dos outros canais. O ZigBee espera operar em ambientes onde o número de redes pode ser bastante denso. Além disso, ele oferece transmissão broadcast e multicast. O protocolo ZigBee alcança alta confiabilidade graças à aplicação das seguintes características (Gislason, 2008a):

1. IEEE 802.15.4 com Offset quadrature phase-shift keying (OQPSK): é um esquema de modulação digital onde a fase da portadora é variada de modo a representar os níveis 0 e 1 , a cada intervalo de bit esta permanece constante. O mesmo ocorre com a frequencia e amplitude do sinal. Direct-Sequence Spread Spectrum (DSSS): é uma técnica de modulação. Os métodos OQPSK e DSSS, uma combinação de tecnologias que dá excelente desempenho em ambientes de baixa relação sinal-ruído;

2. Carrier Sense Multiple Access Collision Avoidance (CSMA-CA): O ZigBee usa o método de acesso ao meio CSMA-CA para incrementar a confiabilidade. Antes de transmitir, o ZigBee escuta o canal. Quando o canal está livre, ele começa a transmitir. Isso diminui a probabilidade de que os rádios transmitam simultaneamente, causando dados corrompidos. CSMA-CA é semelhante ao que as pessoas fazem em conversas. Elas esperam que o outro discursante termine e, então, iniciam seu discurso. Cada pacote é repetido até três vezes (para um total de quatro transmissões). Se houver perda de pacote após a quarta transmissão, o ZigBee informa ao nó emissor o erro na transmissão;

3. Cyclic Redundancy Code (CRC): O ZigBee usa um CRC de 16 bits em cada pacote, chamado soma de verificação do quadro (FCS-Frame Checksum). Isto assegura que os bits de dados estão corretos;

4. Rede Mesh para procurar uma rota confiável: A rede Mesh oferece, essencialmente, três recursos avançados para uma rede sem fio, alcance estendido através de multi salto (multi-hop em Inglês), formação ad-hoc da rede e estabelecimento automático de rota. A rede Mesh permite que dados do nó emissor possam alcançar qualquer outro nó na rede ZigBee, independentemente da distância, enquanto houver rádios suficientes para repassarem a mensagem, 
Figura 2.7a. Ainda na Figura 2.7, suponha que o nó 1 seja o emissor e o nó 3 o destino final, no entanto o nó 3 está fora do raio de alcance do nó 1 . O ZigBee calcula automaticamente o melhor caminho e assim, o nó 1 envia a informação para o nó 2 , que encaminha-o para o nó 3. Agora, suponha que ao longo do tempo, algum impedimento aconteça nessa rota. O nó 2 pode ter sido removido, ter ficado inoperante, ou ainda, pode ser que exista alguma barreira. Isso não prejudica a comunicação da rede. O ZigBee detecta automaticamente a falha e cria uma nova rota em torno da obstrução, Figura 2.7b;

5. Reconhecimentos de extremo a extremo: O ZigBee também fornece reconhecimentos automáticos de extremo a extremo. A aplicação pode saber se um pacote foi recebido pelo outro nó. O ZigBee também filtra qualquer pacote duplicado;

6. Padrão de encriptação: O ZigBee usa o padrão Advanced Encryption Standard (AES). Este padrão, AES-128, é um cifrador de bloco que encripta e decripta pacotes de uma forma que é muito difícil de quebrar. O ZigBee também usa AES-128 para autenticação.

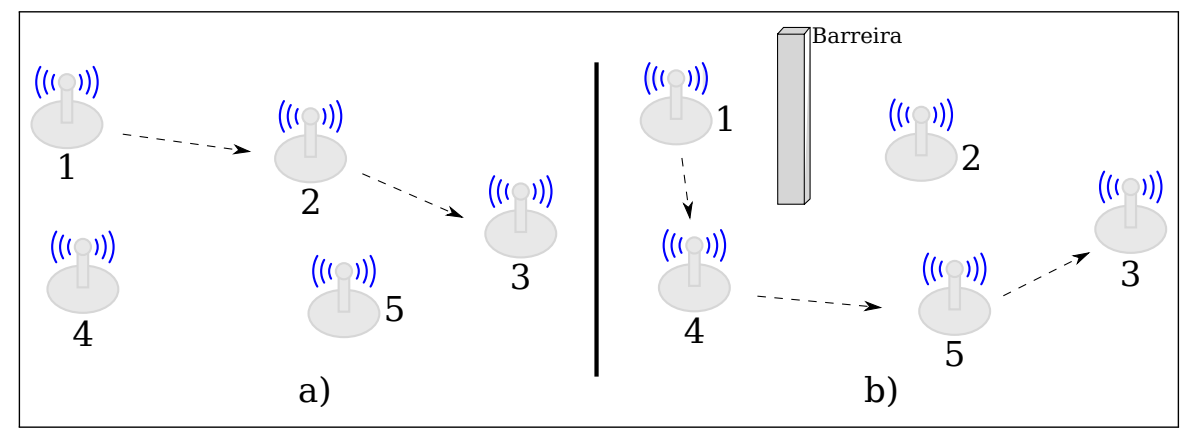

Figura 2.7: Redes mesh ZigBee: A rede mesh é autoconfigurável: a) Estabelece uma rota automaticamente entre a origem e o destino; b) Reestabelece a rota em caso de falha de um nó ou surgimento de um obstáculo. Adaptado de (Gislason, 2008b)

\subsubsection{Arquitetura do ZigBee}

ZigBee é uma pilha de protocolos, que de forma semelhante ao modelo Open System Interconnection (OSI) é constituído em várias camadas, que são independentes umas das outras, veja a Figura 2.8. As camadas física e Media Acces Control (MAC) são definidas pela norma IEEE802.15.4, e o resto das camadas é definido pela aliança ZigBee. O trabalho da camada física (PHY) é traduzir os pacotes a partir de uma série de bytes para o espectro de rádio frequência, e vice-versa. A camada MAC permite que uma rede seja formada, por canais compartilhados, e que os dados sejam transferidos (um só salto), de uma maneira razoavelmente confiável (Farahani, 2011).

ZigBee fornece redes mesh e capacidades multi salto, melhora a confiabilidade de entrega dos pacotes e especifica interoperabilidade de aplicação a aplicação. Esse rádio não usa toda a especificação 802.15.4 MAC/PHY; somente um subconjunto. Por exemplo, o ZigBee não usa os métodos 


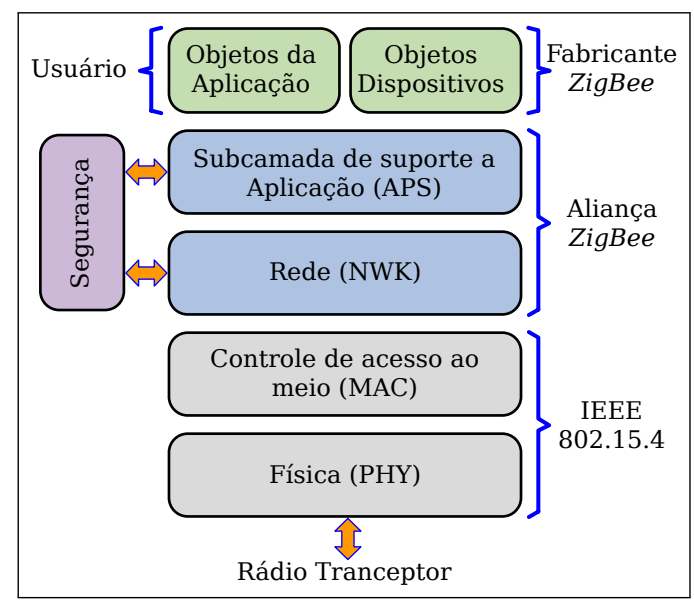

Figura 2.8: Arquitetura do ZigBee: Arquitetura em camadas, semelhante ao modelo OSI. Adaptado de (Farahani, 2011).

beaconing do IEEE802.15.4. Ele é assíncrono, ou seja, qualquer nó pode transmitir a qualquer momento. Um beacon é simplesmente um pacote que tem informação sobre o nó e a rede, sendo usado pelo ZigBee para descobrimento de redes.

A camada de rede (NWK) tem como objetivo principal permitir o uso correto da subcamada MAC e proporcionar uma interface adequada para utilização pela camada de aplicação. Essa camada fornece os métodos necessários para: começar a rede, unir-se a rede, roteamento de pacotes para outros nós na rede, garantir a entrega dos pacotes para o destino final, filtrar pacotes recebidos, criptografar e autenticar. O algoritmo de roteamento usado é Ad Hoc On-Demand Vector Routing (AODV). Nessa camada, implementam-se as diferentes topologias de rede que o ZigBee suporta (árvore, estrela e mesh).

A próxima camada é o suporte para a aplicação que é responsável por manter o papel que o nó atua na rede, filtrar pacotes ao nível da aplicação, manter a relação dos grupos e os dispositivos com os quais a aplicação interage e simplificar o envio de dados para diferentes nós de rede. As camadas de rede e apresentação são definidas pela aliança ZigBee.

O mais alto nível conceitual é a camada de aplicação. Nessa camada está o ZigBee Device Objects (ZDO) que é responsável pela definição do papel do dispositivo na rede, ser coordenador, roteador ou dispositivo final. Essa camada é definida pelos fabricantes de ZigBee. Também nessa camada fica a própria aplicação do usuário.

\subsection{Veículo Aéreo Não Tripulado - VANT}

Segundo a ANAC (ANAC, 2012) (Agência Nacional de Aviação Civil) um VANT (Veículo Aéreo Não Tripulado), também chamado UAV (do inglês Unmanned Aerial Vehicle), é uma:

"Aeronave projetada para operar sem piloto abordo e que não seja utilizada para fins meramente recreativos. Nesta definição, incluem-se todos os aviões, helicópteros e 
dirigíveis controláveis nos três eixos, excluindo-se, portanto, os balões tradicionais e os aeromodelos".

Os VANTs modernos foram inspirados em torpedos aéreos alemães, V1 e V2 (Keane e Carr, 2013), e por aeromodelos radiocontrolados. Inicialmente, os VANTs foram concebidos para fins militares, como patruleamento e monitoramento aéreo, bem como para acesso a regiões inóspitas. No entanto, por causa de sua variedade e versatilidade, essas aeronaves podem ser utilizadas para fins civis, como monitoramento civil e mapeamento agrícola (Finn e Scheding, 2010), agricultura de precisão (Faiçal et al., 2014), entre outros.

Se comparadas com aeronaves convencionais (que são pilotadas por uma pessoa a bordo), os VANTs são uma alternativa barata e segura para uma vasta gama de aplicações (Xiang e Tian, 2011) (Li et al., 2012) (Villas et al., 2013). Um VANT é equipado por vários dispositivos tecnológicos para auxiliá-lo durante o voo, como controlador de voo, computador embarcado, GPS, acelerômetro, giroscópio, magnetômetro, entre outros. Adicionalmente, um VANT pode ser equipado com um módulo de comunicação sem fio, o qual estende as capacidades do veículo, tornando-o um nó volante que pode ser integrado a outras redes.

Os VANTs podem ser classificados em diversas categorias (ou classes), de acordo com seu peso ou seu fim, por exemplo. A ANAC classifica os VANTs em três categorias:

- Classe I: VANTs com peso máximo de decolagem maior que $150 \mathrm{~kg}$;

- Classe II: VANTs com peso máximo de decolagem entre 25 e $150 \mathrm{~kg}$;

- Classe III: VANTs com peso máximo de decolagem inferior a $25 \mathrm{~kg}$.

Há basicamente dois tipos de aeronaves:

Com asa fixa: Seu aspecto é semelhante ao de aviões tradicionais, pois sua sustentação se dá através de asas fixas em relação a sua fuselagem, e

Com asa rotativa: São aeronaves semelhantes aos helicópteros, uma vez que sua sustentação se dá através de asas (neste caso hélices) que se movem em relação a sua fuselagem.

Cada tipo/categoria de aeronave é melhor recomendada dependendo da operação e, no caso de aeronaves de asa rotativa, sua principal característica é a possibilidade de pairar no ar, o que está intimamente relacionada com um dos requisitos deste projeto. Aeronaves de asa rotativa são capazes de realizar manobras em menor espaço aéreo, se comparadas com aeronaves de asa fixa. Outro aspecto chave é a capacidade de decolar e pousar na vertical, habilidade muito útil em situações em que é necessário realizar pouso e decolagem em terrenos irregulares.

O VANT de asa rotativa apresentado na Figura 2.9 foi escolhido para este trabalho devido às suas características, mencionadas anteriormente. 


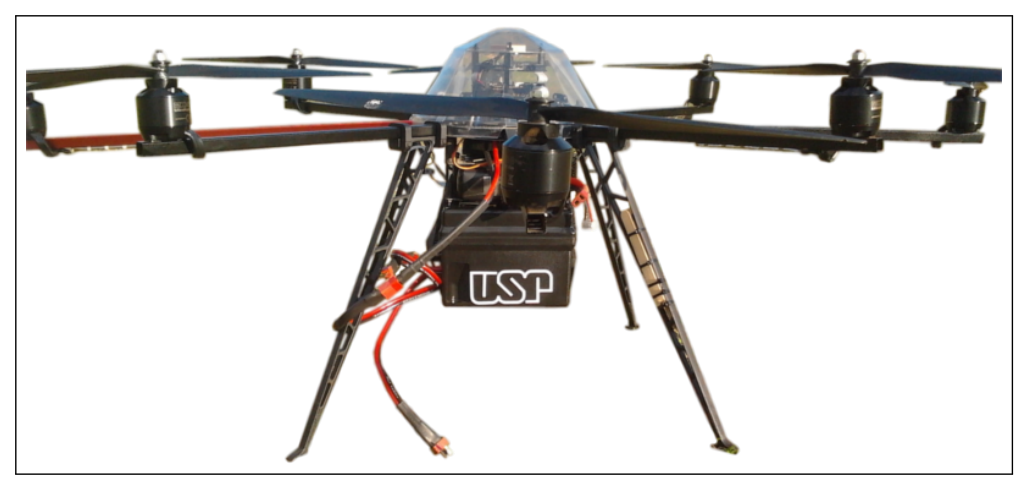

Figura 2.9: VANT MikroKopter Okto. VANT de asa rotativa com oito hélices e de Classe III.

De acordo com os dados coletados pela Teal Group (Teal Group, 2014), empresa de análise de mercado para o setor aeroespacial, VANT é o segmento que apresenta maior taxa de crescimento dentro do setor aeroespacial. Esse mesmo estudo aponta que o mercado mundial deve praticamente dobrar em uma década, com investimentos anuais indo de US\$6,4 bilhões para US $\$ 11,5$ bilhões por ano, totalizando US\$91 bilhões nos próximos dez anos. Em 2014, esse mercado foi dominado por aplicações militares com $89 \%$ e $11 \%$ para fins civis. No entanto, em uma década esses percentuais irão alterar para $86 \%$ com fins militares e $14 \%$ para fins civis. Segundo esse mesmo estudo, o mercado global de sensores e atuadores destinados a VANTs irá saltar de US\$2,8 bilhões em 2014 para US\$5,6 bilhões em 2023.

\subsubsection{O VANT MikroKopter}

MikroKopter é um VANT de asa rotativa, possui modelos de quatro, seis e oito hélices e todos são de Classe III. É uma plataforma aérea universal, de fácil manuseio, muito confiável e extremamente versátil (MikroKopter, 2014a). Vem equipado com Global Positioning System (GPS), Inertial Measurement Unit (IMU), controle de altitude e telemetria (MikroKopter, 2014a). Sua plataforma (hardware e software) é aberta para fins não comerciais (MikroKopter, 2014a).

Possui habilidades de manter altitude e localização autonomamente e voltar automaticamente para a posição de decolagem. Transmite através de telemetria dados como tempo de voo, altitude, alerta de bateria fraca e outros dados para a estação de controle.

Pode também ser programado para cumprir uma determinada rota pré-estabelecida por meio de waypoints $^{6}$. Segundo o fabricante, o modelo de oito hélices possui autonomia de voo de quarenta e cinco minutos com quatro baterias de $5500 \mathrm{mAh}^{7}$, é resistente à água e tem capacidade de carga de até $2,5 \mathrm{~kg}$ (excluindo a bateria).

A placa FlightCtrl é responsável pelo controle da aeronave (i.e. estabilização e acionamento dos motores) (MikroKopter, 2015a), enquanto que a placa NaviCtrl provê habilidades extras ao

\footnotetext{
${ }^{6}$ Coordenadas tridimensionais formadas por latitude, longitude e altura.

${ }^{7}$ Há baterias com capacidade de carga de $6600 \mathrm{mAh}$, portanto o tempo de voo pode ser maior.
} 
MikroKopter na utilização do sistema GPS (posição atual, destino e local de onde decolou). NaviCtrl também é responsável por gerir a variável altura, tensão da bateria, velocidade, entre outras, e também realiza as funções (MikroKopter, 2015b):

PositionHold : Faz com que o MikroKopter tente preservar sua latitude e longitude atuais;

ComingHome : Faz com que o MikroKopter volte à posição de onde decolou, preservando sua altura corrente;

CareFree : Faz com que a direção de Nick e Roll de controle não sejam feitos pela definição frontal, mas pela direção na qual estiver posicionada a parte dianteira do MikroKopter ao ligar os motores.

Waypoint-flight : Permite ao MikroKopter voar autonomamente através de waypoints.

A Figura 2.10 exibe detalhes comuns em toda a linha da fabricante MikroKopter.

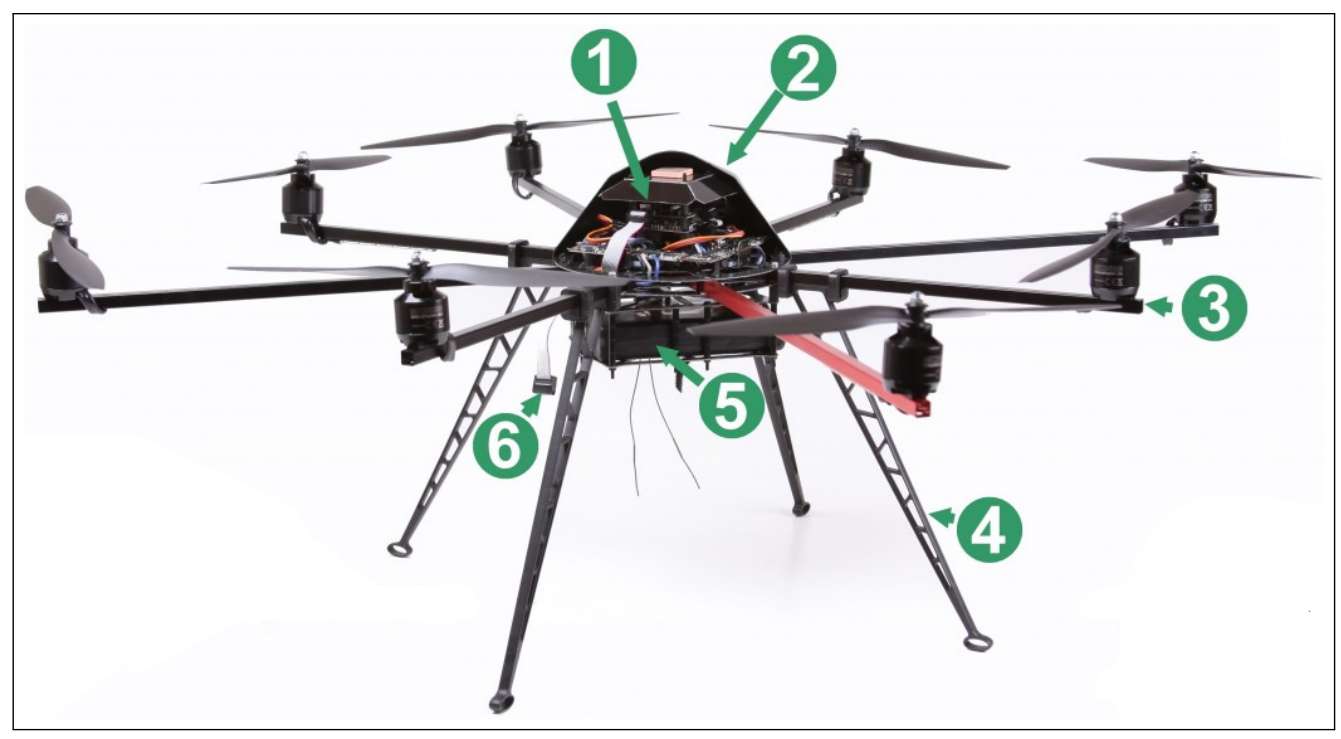

Figura 2.10: Componentes do MikroKopter Okto. 1) Módulos eletrônicos (NaviCtrl, FlightCtrl, MKGPS e ESCs); 2) Capa de proteção; 3) Braços com motores; 4) Trem de pouso; 5) Bateria; 6) Conector para telemetria ou programação. Traduzido de (MikroKopter, 2014b)

Há outros fabricantes de VANTs que proporcionam maior autonomia de voo e maior capacidade de carga, como o RMAX $^{8}$ da Yamaha e a Rotomotion ${ }^{9}$.

O VANT MikroKopter foi escolhido por possuir características inerentes aos objetivos deste estudo. A possibilidade de decolar/pousar na vertical permite que o protótipo inicie e finalize seus voos em locais com o solo irregular. Além disso, esse VANT pode pairar no ar e não necessita de grande espaço aéreo para realizar manobras, quando comparado com VANTs de asas fixas. Essas características fornecem maior flexibilidade ao protótipo de nó volante desenvolvido.

\footnotetext{
${ }^{8}$ http: //rmax.yamaha-motor.com.au

${ }^{9}$ http: //www.rotomotion.com
} 


\subsection{O Minicomputador Raspberry Pi}

O Raspberry Pi é um minicomputador de baixo custo, do tamanho de um cartão de crédito, pode ser conectado a um monitor de computador ou aparelho de TV e usa teclado e/ou mouse padrão. Foi concebido pela Fundação Raspberry $P i$, uma fundação educacional, cujo objetivo é promover a educação de adultos e crianças, em especial na área de computação e assuntos relacionados. Atualmente, há diversos modelos, entretanto, este texto traz detalhes somente do Modelo B, o qual foi utilizado neste trabalho. A tabela 2.1 apresenta as principais características do Raspberry Pi Modelo B.

Tabela 2.1: Características Raspberry Pi (Modelo B - rev 2)

\begin{tabular}{|c|c|}
\hline Preço & US\$35 ( R\$90) \\
\hline $\mathrm{SoC}^{10}$ & Broadcom BCM2835 (CPU, GPU, DSP, SDRAM, USB) \\
\hline CPU & $700 \mathrm{MHz}$ ARM1176JZF-S core (ARM11) \\
\hline GPU & $\begin{array}{l}\text { Broadcom VideoCore IV } \\
\text { OpenGL ES } 2.0 \text { ( } 24 \text { GFLOPS) } \\
\text { MPEG-2 e VC-1, 1080p30 h.264/MPEG-4 AVC }\end{array}$ \\
\hline SDRAM & 512 MB (compartilhado com GPU) \\
\hline USB 2.0 & $2+1$ \\
\hline Video & $\begin{array}{l}\text { RCA composto (PAL e NTSC), HDMI (rev } 1.3 \text { \& 1.4) } \\
\text { Painel LCD via DSI } \\
14 \text { resoluções HDMI }(640 \times 350-1920 \times 1200) \text { e vários padrões PAL e NTSC. }\end{array}$ \\
\hline Áudio & $3.5 \mathrm{~mm}$ jack, HDMI e I2S áudio \\
\hline Armazenamento & $\mathrm{SD} / \mathrm{MMC} / \mathrm{SDIO}$ \\
\hline Rede & 10/100 Ethernet \\
\hline Periféricos & $\begin{array}{l}8 \times \text { GPIO } \\
\text { UART } \\
\text { I2C } \\
\text { SPI } \\
\text { I2S }\end{array}$ \\
\hline Consumo & $700 \mathrm{~mA}(3,5 \mathrm{~W})$ \\
\hline Alimentação & 5V via MicroUSB \\
\hline Tamanho & $85,60 \mathrm{~mm} \times 53,98 \mathrm{~mm}$ \\
\hline Peso & $45 \mathrm{~g}$ \\
\hline $\mathrm{SO}$ & $\begin{array}{l}\text { Arch Linux ARM, Debian, Fedora, FreeBSD, Plan 9, Raspbian OS, RISC OS, } \\
\text { Slackware }\end{array}$ \\
\hline
\end{tabular}

De acordo com (Halfacree e Upton, 2012), o Raspberry Pi é compatível com sistemas operacionais baseados em Linux, e o Raspbian é a distribuição Linux oficial do Raspberry Pi. Qualquer linguagem de programação que possua suporte para o processador ARMv6 pode ser utilizada no Raspberry Pi, tais como Python, C/C++, Java, Scratch e Ruby. Todas essas linguagens estão instaladas por padrão (Raspberry Pi Foundation, 2014). A Figura 2.11 apresenta o minicomputador Raspberry Pi.

A adoção do minicomputador Raspberry $P i$ se deu em razão de seu tamanho reduzido, pinos de GPIO, UART, I2C, USB, baixo consumo energético e vasta documentação disponível na Internet. Utilizou-se o Raspberry P $i$, embarcado no VANT, para o processamento de informações e coordenação do microcontrolador Arduino.

\footnotetext{
${ }^{10}$ System on Chip
} 


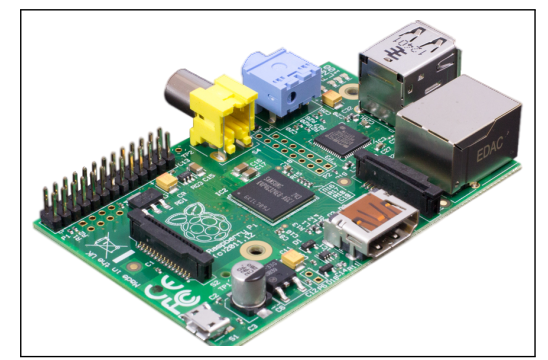

Figura 2.11: Raspberry Pi Modelo B (Ferreira, 2013): Aspecto físico do Raspberry Pi, um minicomputador capaz de executar o SO Linux, possuindo o tamanho de um cartão de crédito.

\subsection{O Microcontrolador Arduino}

Arduino é uma placa de controle para a entrada de dados (leitura de sensores) e saída de dados (acionamento de atuadores). Foi concebido como projeto de ensino pelo professor Massimo Banzi, em 2005, na Itália. O Arduino tem clock de $16 \mathrm{Mhz}$, composto por um cristal oscilador, um regulador de tensão de $5 \mathrm{~V}$, botão de reset, plugue de alimentação, pinos conectores, e LEDs. Além disso, o Arduino fornece alimentação enquanto estiver conectado ao computador e sua tensão de alimentação pode variar de $7 \mathrm{~V}$ à $12 \mathrm{~V}$.

O Arduino possui um conversor USB/UART o qual permite que informações, e dados de programação do microcontrolador, sejam trocadas entre um computador e o Arduino. A linguagem de programação desse microcontrolador é a Wiring, baseada em C/C++ (Arduino, 2014). A Figura 2.12 apresenta um dos vários Arduinos disponíveis no mercado.

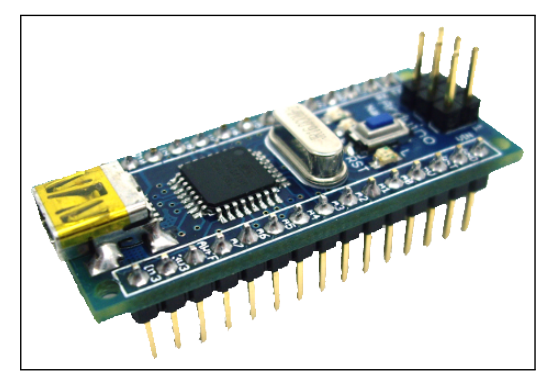

Figura 2.12: Arduino nano V3.0 (Arduino, 2014): Aspecto físico do Arduino Nano.

Uma das características que permitiu sua popularização foi a possibilidade de estender suas funcionalidades originais através de shields. Shields são placas eletrônicas modulares que podem ser plugadas a um Arduino para estender suas capacidades, o que torna o sistema modular e expansível. Pode-se combinar várias dessas shields para que o Arduino possa desempenhar o papel almejado. Para ilustrar tal situação, a Figura 2.13 mostra uma possível configuração de um Arduino conectado a duas shields.

O microcontrolador Arduino foi escolhido por ser amplamente difundido e possuir uma vasta documentação disponível na Internet. Utilizou-se o Arduino, juntamente com a Power Meter Shield (ver Seção 4.2.1), para aquisição de dados utilizados no cálculo do consumo energético do 


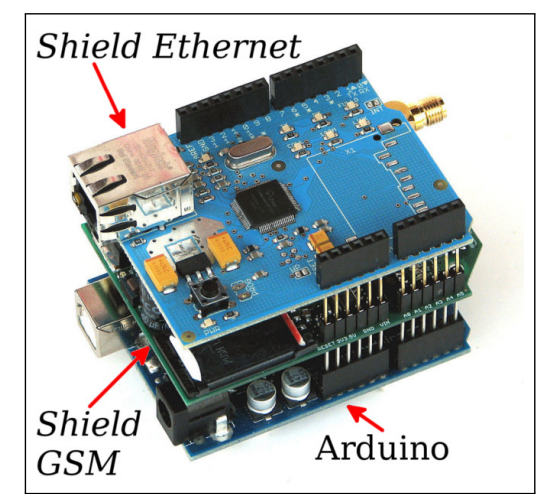

Figura 2.13: Expansão das funcionalidades do Arduino: A shield superior conecta o Arduino a uma rede Ethernet, enquanto que a inferior conecta o Arduino a uma rede GSM. Essa configuração pode transformar o Arduino em um gateway ${ }^{11}$. Adaptado de (HW Kitchen, 2015)

ZigBee. Os elementos VANT, Raspberry Pi, Arduino, Power Meter Shield e ZigBee são a base do nó volante desenvolvido neste trabalho.

\subsection{Cálculo do consumo energético}

O cálculo do consumo energético do módulo de rádio ZigBee foi realizado através da equação (2.1), sendo que $V_{(t)}$ é a tensão e $I_{(t)}$ é a corrente lida no tempo $t$. O intervalo de integração vai de 0 até $x$, sendo que $x$ corresponde ao tempo total de execução da operação. O resultado desta equação é a quantidade de Joules consumidos de 0 até $x$ segundos.

$$
\text { Joules }=\int_{0}^{x} V_{(t)} I_{(t)} \mathrm{d} t
$$

O joule, cujo símbolo é J, é a unidade usualmente utilizada para medir energia mecânica, ou seja, trabalho. Também é utilizada para medir energia térmica (calor). No Sistema Internacional de Unidades (SI), todo trabalho ou energia são medidos em joules.

\footnotetext{
${ }^{11}$ Dispositivo intermediário geralmente destinado a interligar redes, separar domínios de colisão, ou traduzir protocolos.
} 



\section{Trabalhos Relacionados}

O artigo de (Daniel et al., 2009) descreve o AirShield, uma enxame de VANTs autônomos para patrulha, auxílio e prevenção em situações de emergência. O VANT é equipado com sensores leves que são distribuídos para coletar dados/informações relevantes na área em que houve o incidente. Os VANTs sobrevoam a região de desastre para coletar dados e enviá-los à central de comando. É um projeto multidisciplinar, integra aspectos de decisão, modelo de propagação de aerossol e é especialmente desenvolvido para o auxílio de bombeiros. No entanto, não adquire imagens, fator que pode ser decisivo no auxílio de resgates. A comunicação entre os VANTs é feita através de IEEE802.11s, que possui baixo alcance se comparada com a do ZigBee, o que limita as distâncias entre os VANTs.

(Hauert et al., 2010) descreve o projeto SMAVNET, que cria uma rede de comunicação em áreas de desastre através de VANTs. O projeto utiliza VANTs para distribuir nós de uma rede em uma área de desastre a fim de estabelecer comunicação com equipes de resgate. Foram construídos alguns protótipos reais de VANTs com módulos de posicionamento global (GPS) e transmissor ZigBee. Os VANTs são de asa fixa, o que proporciona maior autonomia de voo se comparados com VANTs de asa móvel. Os protótipos foram avaliados em ambiente real e externo, o que contribui para uma avaliação mais precisa do comportamento do sistema em uma situação real. Entretanto, os VANTs não são autônomos e não possuem câmera, fatores limitantes para o sucesso de operações de resgate.

A proposta do artigo (de Freitas et al., 2010) é a utilização de VANTs para dar suporte/conectividade para a RSSF instalada em terra. Os VANTs utilizados são de asa fixa e atuam de maneira a evitar ilhas isoladas na rede. A principal contribuição é a investigação de uma solução para prover a conectividade entre os VANTs e as sub-redes, formadas pelos nós da RSSFs em solo. Para o 
desenvolvimento desse trabalho, o autor entende que a RSSF em solo foi abstraída, pois o foco é a da atuação dos VANTs que não fazem roteamento e/ou transporte de dados e não trabalham com imagens. A validação ocorreu de forma simulada.

(Morgenthaler et al., 2012) apresenta o UAVNet, um framework para a implantação autônoma de uma RSSF através de pequenos VANTs. Cada VANT atua como um nó nessa rede e que utiliza o protocolo IEEE802.11s. O protótipo UAVNet implementado é capaz de interligar autonomamente dois sistemas finais. O software desenvolvido inclui a funcionalidade básica para controlar o VANT e configurar, implantar, gerenciar e monitorar um RSSF. Provê plataforma para teste de algoritmos complexos para controle topológico e protocolos de roteamento para uma rede formada por VANTs. Entretanto, possui baixa portabilidade e é incapaz de acrescentar outras formas de comunicação, como ZigBee ou WAVE. Não possui câmera e não faz planejamento de rotas autonomamente.

O trabalho de (Tuna et al., 2012) apresenta estratégias para usar VANTs na implementação de RSSF para monitoramento pós-desastre. Nas estratégias estão determinação de rotas, posicionamento e melhores locais para depositar sensores sem fio. A proposta utiliza VANTs para espalhar sensores sem fio na área de cobertura da rede RSSF. Os esforços foram direcionados para a localização e navegação do VANT. O sistema proposto foi simulado com o simulador USARSim para avaliar o desempenho de localização e navegação de um VANT responsável pela disposição da RSSF. Entretanto, esse estudo não trabalha com imagens, roteamento e/ou transporte de dados e não especifica qual foi o tipo de rádio utilizado.

(Sun et al., 2012) apresenta um algoritmo baseado em centroide, centro de massa, para localizar as posições das sombras na área de cobertura de uma RSSF. Essas sombras podem causar perda dos dados capturados ou falhas no monitoramento. Com isso, o VANT foi usado para realizar a readaptação dos nós da rede. O artigo assume o problema de planejamento de rota como o Traveling Salesman Problem (TSP), que pode ser resolvido por algoritmos genéticos. Assim, o algoritmo detecta regiões de sombra numa RSSF e cobre-as com o uso de VANTs, sem a capacidade de coletar dados, nem de disseminar imagens.

(Martinez-de Dios et al., 2013) descreve um método cooperativo entre VANTs e RSSF para coletar dados. O método apresenta dois comportamentos cooperativos:

1. Resultados de operação da RSSF são usados para atualizar o plano de voo do VANT;

2. A trajetória do VANT é considerada na operação da rede para melhorar o desempenho da coleta de dados.

O método foi validado mediante vários experimentos reais feitos com um só VANT. Esse método avalia o impacto da velocidade do VANT na taxa de comunicação sem fio (IEEE802.15.4) e não realiza coleta de dados/informações, nem disseminação de imagens.

O trabalho de (Marinho et al., 2013) fornece uma solução para o problema de ter grupos isolados de sensores que não podem entregar seus dados coletados. Tal solução é baseada em técnicas 
cooperativas múltipla entrada múltipla saída (MIMO) para fornecer comunicação entre sensores estáticos e em uma RSSF composta de nós de retransmissão e VANTs. Resultados das simulações mostraram evidências dos benefícios de combinar as duas técnicas, em termos de conectividade da rede, em comparação com a utilização isolada de cada uma dessas técnicas. Entretanto, não faz o transporte de dados, nem trabalha com imagem.

\subsection{Discussão dos trabalhos relacionados}

De acordo com os trabalhos relacionados, o uso de VANTs em RSSFs não é novidade e há alguns trabalhos que investigam isso. É importante salientar que nenhum estudo explora VANTs para proporcionar maior grau de resiliência para RSSFs para agir contra catástrofes naturais (por exemplo, inundações) ou faz avaliações com base em dispositivos reais. Outra deficiência dos trabalhos relacionados é a despreocupação com o consumo energético do VANT, fator impactante na autonomia de voo deste e nas condições favoráveis para a comunicação do VANT com a RSSF. A Tabela 3.1 faz um resumo das principais diferenças entre este trabalho e os trabalhos relacionados.

Por esses motivos, este trabalho inclui experiências reais que envolvem tanto VANTs prototipados quanto RSSF implantada, ou seja, este trabalho não faz uso de validação através de ferramentas de simulação. O VANT testado foi equipado com um rádio ZigBee e um Raspberry Pi para realizar a validação da comunicação com a RSSF instalada.

A maior diferença entre o protótipo proposto em relação aos protótipos da literatura é a habilidade para monitorar o consumo energético dos componentes do VANT, pois informações sobre o consumo energético em tempo real são muito importantes para se saber se o VANT será capaz de cumprir sua missão; e a transmissão de imagens via streaming para uma estação base.

Tabela 3.1: Resumo das principais características dos trabalhos relacionados

\begin{tabular}{|c|c|c|c|c|c|c|}
\hline Autor & $\begin{array}{c}\text { Faz análise do } \\
\text { consumo } \\
\text { energético }\end{array}$ & Câmera & Ambiente real & ZigBee & $\begin{array}{l}\text { VANT atua como } \\
\text { roteador }\end{array}$ & Autônomo \\
\hline (Daniel et al., 2009) & $x$ & $x$ & $x$ & $x$ & $x$ & $\sqrt{ }$ \\
\hline (Hauert et al., 2010) & $x$ & $x$ & $\checkmark$ & $\sqrt{ }$ & $x$ & $x$ \\
\hline (de Freitas et al., 2010) & $x$ & $x$ & $x$ & $x$ & $\sqrt{ }$ & $\sqrt{ }$ \\
\hline (Morgenthaler et al., 2012) & $x$ & $x$ & $\sqrt{ }$ & $x$ & $\sqrt{ }$ & $x$ \\
\hline (Tuna et al., 2012) & $x$ & $x$ & $x$ & Não informa & $x$ & $\checkmark$ \\
\hline (Sun et al., 2012) & $x$ & $x$ & $x$ & $x$ & $\sqrt{ }$ & $\sqrt{ }$ \\
\hline (Martinez-de Dios et al., 2013) & $x$ & $x$ & $\sqrt{ }$ & $x$ & $\sqrt{ }$ & $\sqrt{ }$ \\
\hline (Marinho et al., 2013) & $x$ & $x$ & $x$ & $x$ & $\sqrt{ }$ & $\checkmark$ \\
\hline Este trabalho & $\sqrt{ }$ & $\sqrt{ }$ & $\checkmark$ & $\sqrt{ }$ & $\sqrt{ }$ & $\sqrt{ }$ \\
\hline
\end{tabular}





\section{Provendo Resiliência a uma RSSF através de VANT}

Soluções baseadas em redundância de equipamentos, além de serem mais dispendiosas, podem não garantir tolerância a falhas em uma RSSF. O uso de VANT para prover resiliência a uma RSSF garante maior possibilidade de êxito devido à capacidade dessas aeronaves sobrevoarem regiões onde veículos terrestres e aquáticos não possam alcançar. O acionamento do VANT é automatizado através da detecção de falhas na RSSF. Seu voo é autônomo e possui autonomia suficiente para assistir uma região afetada; Para tornar essa arquitetura proposta viável, desenvolveu-se o UAV Brain, um módulo computacional com capacidade de comunicação sem fio, que fica alojado no VANT para transformá-lo em um nó volante. O UAV Brain é composto por minicomputador Raspberry Pi, rádio transceptor ZigBee e o Power Monitor (união de Arduino com Power Meter Shield). O Power Monitor monitora o consumo energético de componentes do nó volante; Para validação da proposta, utilizou-se a arquitetura cliente-servidor, na qual o nó móvel atuou como roteador da rede. Os experimentos foram realizados com o planejamento fatorial completo para garantir todas as combinações possíveis. As variáveis de resposta utilizadas foram o consumo energético do ZigBee, o RTT e a taxa de perdas de pacotes; Coube ao nó cliente ser o coordenador dos experimentos e registrar as perdas de pacotes, ao nó volante coletar dados de consumo energético de seu comunicador e ao nó servidor responder as requisições realizadas pelo nó cliente. 


\subsection{Proposta}

Uma estratégia para aumentar a tolerância a falhas em uma RSSF sem a utilização de VANT é a adoção de nós extras, a replicação de componentes internos de um nó sensor e o uso de comunicação através da terceira geração (3G) de telefonia móvel. Entretanto, essa solução pode degradar a bateria mais rapidamente, devido à necessidade de mais dados a serem transmitidos e/ou à alimentação de dispositivos extras, além do acréscimo financeiro envolvido para custear essa demanda por novos equipamentos, componentes e implantação de novos nós sensores. Entretanto, essas alternativas não garantem a tolerância a falhas devido as condições do ambiente no momento do desastre. Por outro lado, o uso de VANT para prover resiliência a uma RSSF adiciona alguns recursos extras importantes, tais como:

i Através de uma câmera instalada no VANT, pode-se transmitir imagens em tempo real para equipes de resgate;

ii O VANT pode atuar como mula de dados entre nós comunicantes distantes;

iii O VANT pode mapear as áreas de desastre afetadas durante a realização de outra tarefa;

iv O VANT pode navegar por regiões inacessíveis a outros tipos de veículos, como carros e barcos. Essas regiões podem ser riachos, áreas afetadas por inundações, deslizamento de terras e terremotos.

Como mencionado anteriormente na Seção 2.1.1, os pacotes de dados na RSSF e-NOÉ são enviados dos nós sensores em direção ao nó Sink através da transmissão multi salto. Cada nó sensor recebe o pacote de seu vizinho, adiciona seus dados e transmite para o próximo nó sensor em direção ao nó Sink. Esses pacotes provenientes dos nós sensores são emitidos a cada cinco minutos. Durante o período crítico (i.e. período de chuva torrencial alertado pelo pluviômetro), estabelece-se um tempo limite para checar se um pacote chegou ao nó Sink nesse intervalo de tempo.

Se esse pacote não chegar, então o nó volante se aciona automaticamente para cobrir a comunicação entre os dois nós. Através do número de identificação dos sensores nos pacotes, é possível identificar qual nó sensor deixou de funcionar e com isso, acionar o nó volante para que ele vá até a posição do nó sensor defeituoso.

O VANT MikroKopter é capaz de voar autonomamente através de uma rota pré-programada através de waypoints. Como a posição de cada nó sensor da RSSF é conhecida, é possível definir uma rota a qual o nó volante irá percorrer para reestabelecer a comunicação entre dois nós sensores.

Pode-se estabelecer o melhor local para o nó volante pairar no ar, caso não seja necessário atuar como mula de dados, ou melhor ponto de retorno, caso seja necessário atuar como mula de dados, através da intensidade de sinal de rádio (ou RSSI - Received Signal Strength Indication). 
A velocidade de voo do MikroKopter pode ser controlada e varia de $0.1 \mathrm{~m} / \mathrm{s}$ até $6 \mathrm{~m} / \mathrm{s}$ e, com isso, pode-se calcular o tempo para cobertura do nó sensor defeituoso.

O tempo de voo do VANT MikroKopter depende muito das condições ambientais (e.g. ventos), carga e velocidade de voo. Segundo o fabricante, o MikroKopter Okto, VANT de oito hélices, equipado com quatro baterias de $5500 \mathrm{mAh}^{1}$ possui uma autonomia de voo de quarenta e cinco minutos, tempo suficiente para assistir uma região afetada. Por esses motivos, o conhecimento do perfil de consumo energético das entidades envolvidas pode ser vital para o prolongamento da missão.

\subsection{Protótipo de Nó Volante}

Além de seus elementos de controle tradicionais (controladores de voo, computador de bordo, módulo GPS, sensores etc.), o VANT pode ser equipado com rádio transmissor/transceptor/receptor para comunicação sem fio para torná-lo apto a se comunicar com outros elementos de uma rede de dados. Nesse cenário, o VANT se torna um nó volante ${ }^{2}$ dessa rede de dados (Braun et al., 2010). Assim, o VANT é capaz de tomar decisões com base nas informações recebidas pela rede.

Os VANTs de asas rotativas possuem características inerentes aos objetivos a este trabalho. A possibilidade de decolar e pousar com orientação vertical, permite que o protótipo inicie e finalize seus voos em ambientes com o solo irregular. Além disso, estes modelos podem pairar e necessitam de espaços aéreos menores para realizar manobras, quando comparados com VANTs de asas fixas. Essas características fornecem maior flexibilidade ao protótipo. A Figura 4.1 apresenta o VANT usado na construção do protótipo de um nó volante para RSSF.

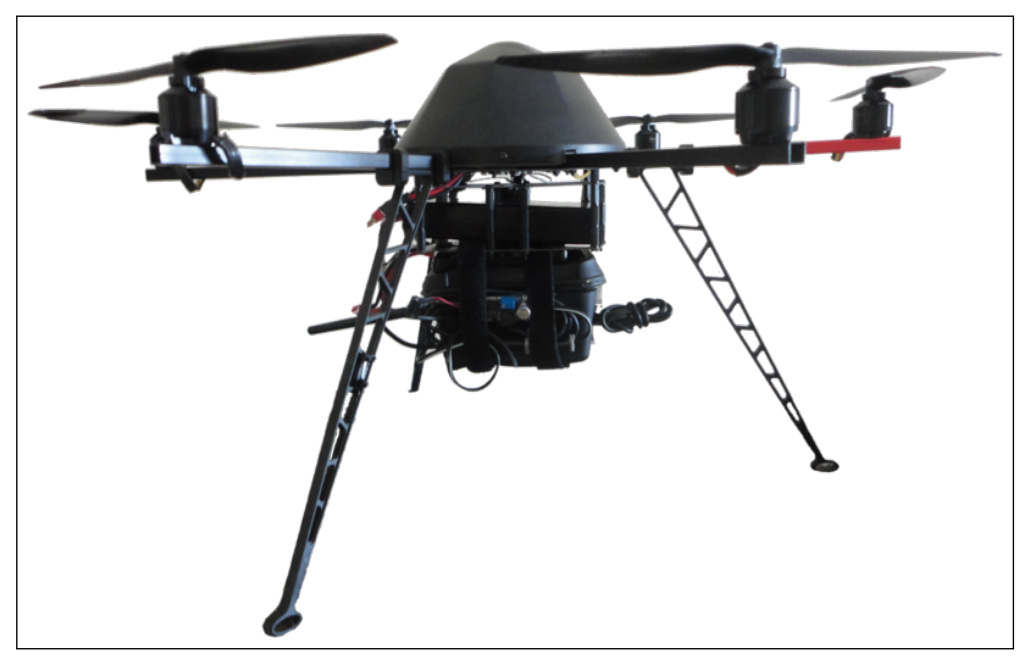

Figura 4.1: Primeiro protótipo de nó volante desenvolvido: MikroKopter Hexa equipado com o $U A V$ Brain entre seus trens de pouso.

\footnotetext{
${ }^{1}$ Há baterias de $6600 \mathrm{mAh}$, logo, o tempo de voo pode ser maior.

${ }^{2}$ Nó que possui a faculdade de voar.
} 


\subsubsection{UAV Brain - O módulo computacional do VANT}

Ainda na Figura 4.1, é possível observar o módulo responsável por toda a comunicação entre o protótipo e a RSSF, o UAV Brain localizado entre os trens de pouso. Assim, este protótipo se torna um nó volante capaz de rotear/transportar mensagens com objetivo de superar obstáculos (ex. servir como roteador/repetidor para aumentar o alcance do sinal afim de suprir a falha de algum nó sensor fixo) e também torna-se apto a ser empregado como uma mula de dados (ex. coleta e transporte de dados da RSSF até a central de processamento).

A Figura 4.2 traz detalhes de implementação do protótipo UAV Brain utilizado para a realização dos experimentos. O ZigBee, veja destaque Figura 4.2-(i e ii)A, é o agente responsável pela transmissão de dados sem fio. O Arduino, em conjunto com a Power Meter Shield (destaques na Figura 4.2-(ii)B e Figura 4.2-(ii)D respectivamente), atua no monitoramento do consumo de energia elétrica do ZigBee. O Raspberry Pi, em evidência na Figura 4.2-(ii)C, é o agente computacional, ao qual são delegadas as funções de registro do log de consumo energético do ZigBee e o roteamento dos pacotes provenientes da rede sem fio. A Figura 4.3 traz a arquitetura de hardware construído.

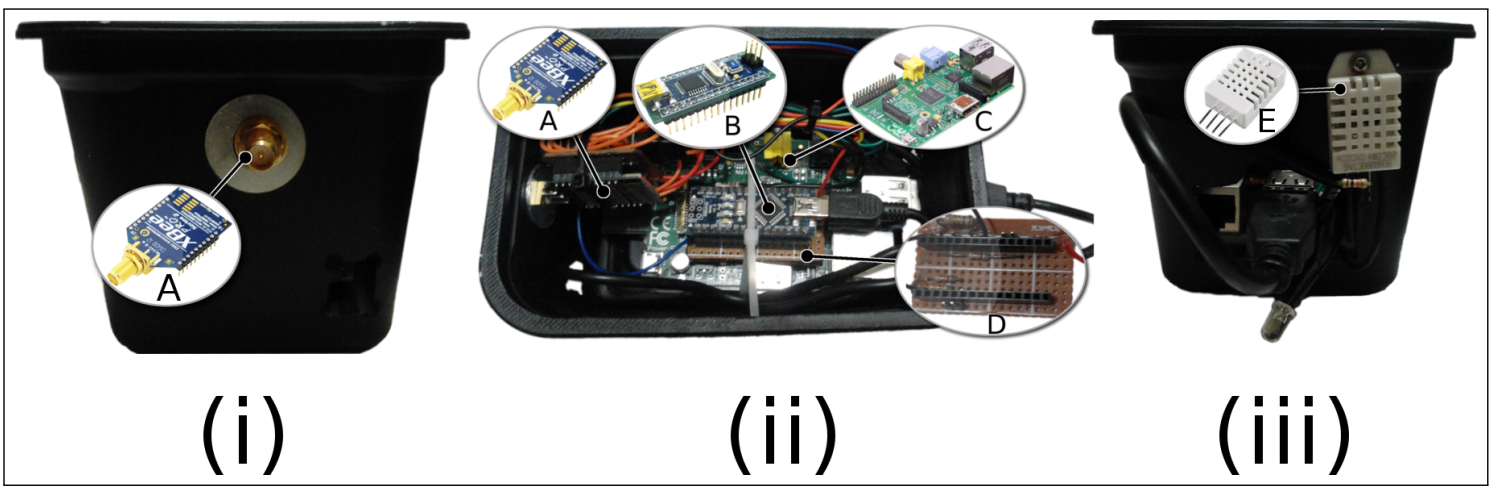

Figura 4.2: $\boldsymbol{U A V}$ Brain: (i) Vista frontal; (ii) Vista superior; (iii) Vista traseira; A) Rádio transceptor ZigBee; B) Arduino Nano; C) Raspberry Pi; D) Power Meter Shield; E) Sensor de umidade e temperatura;

A Power Meter Shield possui a finalidade de auxiliar o Arduino na medição do consumo energético de equipamentos eletrônicos de baixa potência. Não possui origem comercial, foi confeccionada pelo autor deste trabalho e seu diagrama esquemático pode ser visto na Figura 4.4.

O pino GNDin deve ser conectado ao GND da fonte de alimentação, enquanto que o GNDout deve ser ligado ao GND do equipamento a ser analisado. O pino Vin deve ser conectado à tensão de alimentação do ZigBee. Como visto na Equação 2.1, na página 21, a medição do consumo energético é dependente de três fatores: tensão, corrente e tempo. Em sistemas eletrônicos a variável mais custosa para se mensurar é o tempo, dado a rapidez em que os eventos ocorrem. Para superar esse obstáculo, elaborou-se um dispositivo orientado a eventos, o Power monitor (combinação de Arduino e Power Meter Shield). 


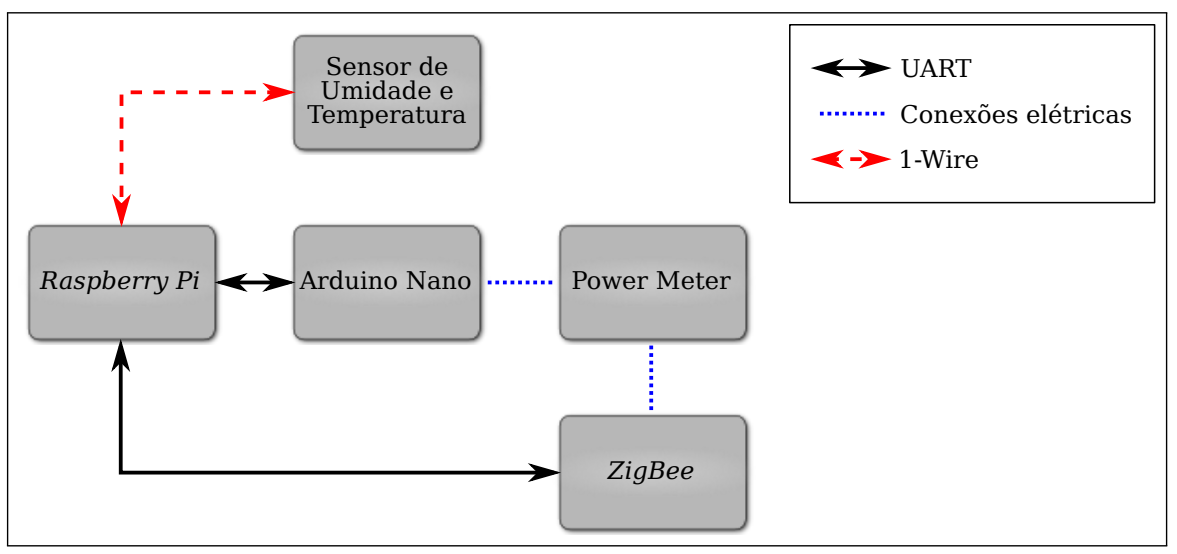

Figura 4.3: Arquitetura de hardware do UAV Brain: Minicomputador Raspberry Pi como agente computacional, monitor de consumo energético formado pelo Arduino Nano e Power Meter, ZigBee e sensor de Umidade e Temperatura.

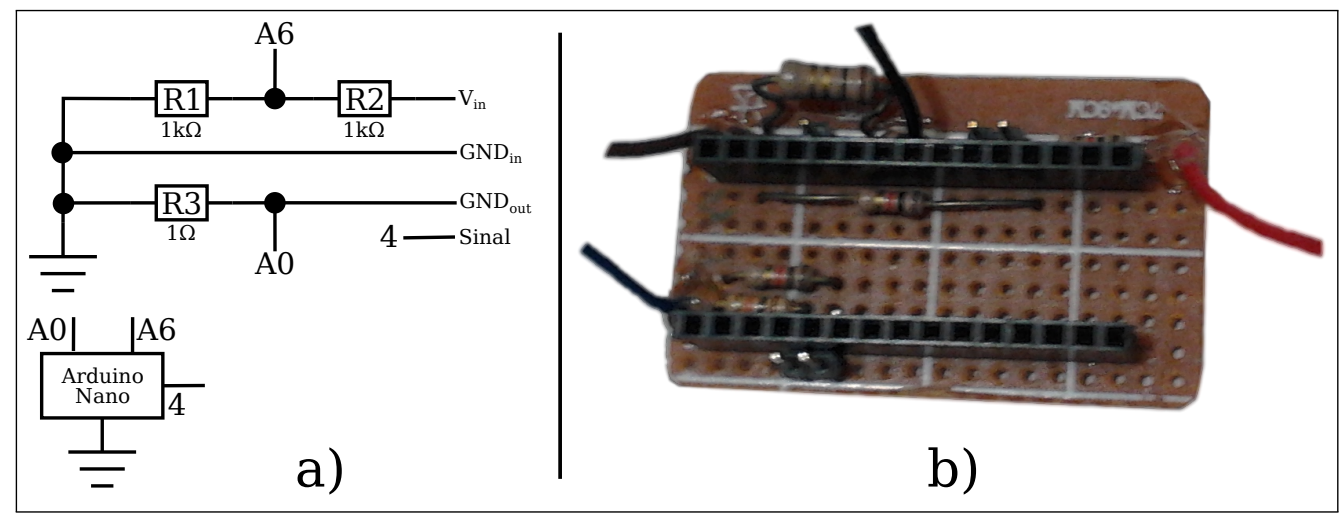

Figura 4.4: Power Meter Shield: Shield para monitorar o consumo de energia do ZigBee. a) Diagrama esquemático; b) Aspecto físico da placa confeccionada.

O pino Sinal é utilizado para indicar ao Arduino o momento para realizar as leituras. Se o sinal estiver em nível baixo, realiza-se a leitura do consumo energético. Se o sinal estiver em nível alto, os dados não são coletados. Esse chaveamento de operação é realizado através de interrupção, para que ocorra de maneira mais rápida possível e garanta a precisão necessária para mensurar o consumo energético.

\subsection{Ambiente de experimentação}

Com a intenção de obter resultados mais fidedignos, realizaram-se os experimentos em ambiente real, como ilustrado na Figura 4.5. Nesse cenário, utilizaram-se três agentes, sendo eles: (i) o cliente; (ii) o nó volante (VANT); e (iii) o servidor. O cliente (Rótulo b da Figura 4.5) responsabilizou-se por realizar as requisições ao servidor, bem como coordenar as ações do nó volante (Rótulo a da Figura 4.5). O nó volante atuou como roteador de pacotes entre o cliente e 
o servidor, além de monitorar o consumo de energia de seu rádio transceptor ZigBee. O servidor (Rótulo f da Figura 4.5) possui a função de responder as requisições realizadas pelo cliente.

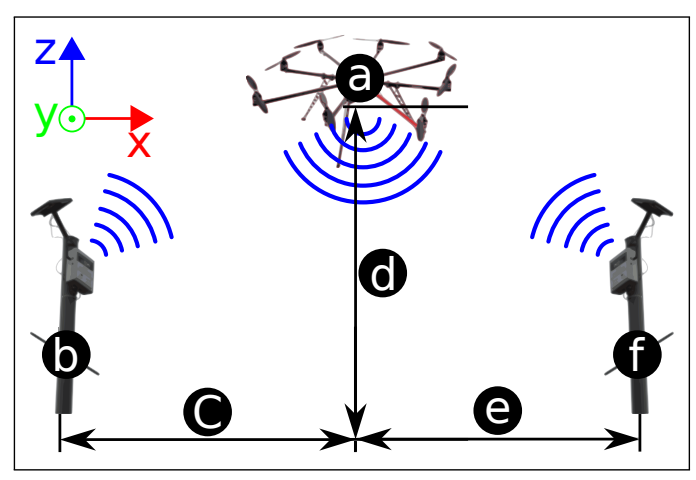

Figura 4.5: Cenário dos experimentos (arquitetura cliente-servidor): a) Nó volante (VANT);

b) Cliente; c) Distância entre o cliente e a projeção do nó volante no chão; d) Altura do nó volante; e) Distância entre o servidor e a projeção do nó volante no chão; f) Servidor.

Utilizaram-se três variáveis de resposta para a avaliação de desempenho:

1. Consumo energético, para descobrir quantos Joules foram consumidos pelo ZigBee embarcado no VANT;

2. Tempo de ida e volta da mensagem (em Inglês Round-Trip delay Time - RTT), o qual mostra o tempo de propagação da mensagem entre o nó transmissor e sua resposta vinda do servidor que passam pelo VANT;

3. Taxa de perdas de pacotes, que representa o percentual de pacotes perdidos ao longo das transmissões.

Realizou-se a avaliação de desempenho do nó volante com os conjuntos de fatores primários sumarizados pela Tabela 4.1. Em razão disso, avaliou-se a proposta com o uso do nó volante (em solo e em voo), distância entre os nós (30 metros e 80 metros) e o ganho da antena embarcada no nó volante (3dBi e $10 \mathrm{dBi})$. Para possibilitar a realização de todas as combinações dos conjuntos de fatores, utilizou-se o planejamento fatorial completo. Replicou-se 33 vezes cada conjunto de experimentos, e realizou-se uma comparação estatística entre os conjuntos através do teste de normalidade de Shapiro-Wilk ${ }^{3}$ e do teste de ordenação de Wilcoxon ${ }^{4}$.

Coletaram-se também outras infirmações relevantes, descritas pela Tabela 4.2, que podem ter influenciado a avaliação de desempenho.

\footnotetext{
${ }^{3}$ Teste para verificar se os dados pertencem a uma distribuição Gaussiana.

${ }^{4}$ Teste estatístico e não paramétrico utilizado para comparar duas amostras relacionadas e determinar se existem diferenças entre elas.
} 
Tabela 4.1: Conjunto de fatores primários avaliados: Esta tabela está relacionada com a Figura 4.5 (página 32), onde VANT corresponde ao item d e Distâncias é equivalente aos itens c e

\begin{tabular}{c||ccc}
\hline \multicolumn{5}{c}{ Experimento } & VANT & Distâncias & Antena \\
\hline \hline E1 & solo $(0 \mathrm{~m})$ & $30 \mathrm{~m}$ & $3 \mathrm{dBi}$ \\
E2 & solo $(0 \mathrm{~m})$ & $30 \mathrm{~m}$ & $10 \mathrm{dBi}$ \\
E3 & solo $(0 \mathrm{~m})$ & $80 \mathrm{~m}$ & $3 \mathrm{dBi}$ \\
E4 & solo $(0 \mathrm{~m})$ & $80 \mathrm{~m}$ & $10 \mathrm{dBi}$ \\
E5 & $\operatorname{voo~}(5 \mathrm{~m})$ & $30 \mathrm{~m}$ & $3 \mathrm{dBi}$ \\
E6 & $\operatorname{voo}(5 \mathrm{~m})$ & $30 \mathrm{~m}$ & $10 \mathrm{dBi}$ \\
E7 & $\operatorname{voo~}(5 \mathrm{~m})$ & $80 \mathrm{~m}$ & $3 \mathrm{dBi}$ \\
E8 & $\operatorname{voo~}(5 \mathrm{~m})$ & $80 \mathrm{~m}$ & $10 \mathrm{dBi}$ \\
\hline
\end{tabular}

Tabela 4.2: Fatores secundários: Fatores presentes que podem ter influenciado os resultados.

\begin{tabular}{l||l}
\hline \multicolumn{1}{c||}{ Fatores secundários } & Informações \\
\hline \hline Canal do ZigBee & 16 \\
Temperatura ambiente & $(26,98 \pm 0,07)^{\circ} \mathrm{C}$ \\
Umidade relativa do ar & $(52,15 \pm 0,11) \%$ \\
Taxa de leitura do consumo energético & 170 leituras/segundo \\
Taxa de comunicação PC/ZigBee & $9600 \mathrm{bps}$ \\
Potência de transmissão do ZigBee & $10 \mathrm{dBm}$ \\
& \\
\hline
\end{tabular}

\subsubsection{Metodologia}

Realizou-se a comunicação entre os rádios ZigBee da rede em modo API. Para facilitar a comunicação entre o Raspberry Pi e o ZigBee, utilizou-se a biblioteca libxbee (Attie, 2014). Essa biblioteca foi desenvolvida em $\mathrm{C} / \mathrm{C}++$ com o intuito de auxiliar a utilização de módulos XBee da Digi em modo API. Sua filosofia é tornar o desenvolvimento das comunicações mais fácil, sem a necessidade de endereçar cada pacote, ou realizar filtros.

Programaram-se os três agentes envolvidos no experimento de acordo com os diagramas apresentados nas Figuras 4.6, 4.7, 4.8 e 4.9. A Figura 4.6 traz o diagrama de atividades executado no nó cliente, responsável pela coordenação dos experimentos e das atividades executadas pelo nó volante. O nó cliente realiza o setup do ZigBee, ou seja, determina a porta e taxa de comunicação, bem como o endereço de destino, envia um pacote por requisição até que o número de requisições atinja o número de replicações desejado.

A Figura 4.7 traz o diagrama de atividades executado pelo Raspberry Pi alojado no nó volante. Primeiramente, faz-se o setup do ZigBee para criar as duas conexões. Os dados provenientes de uma conexão são repassados a outra conexão, exceto no caso de uma configuração. A configuração é necessária para garantir o sincronismo do sistema.

A Figura 4.8 traz o diagrama de atividades executado no nó volante, onde o Arduino espera por um sinal de interrupção para realizar as medições. 


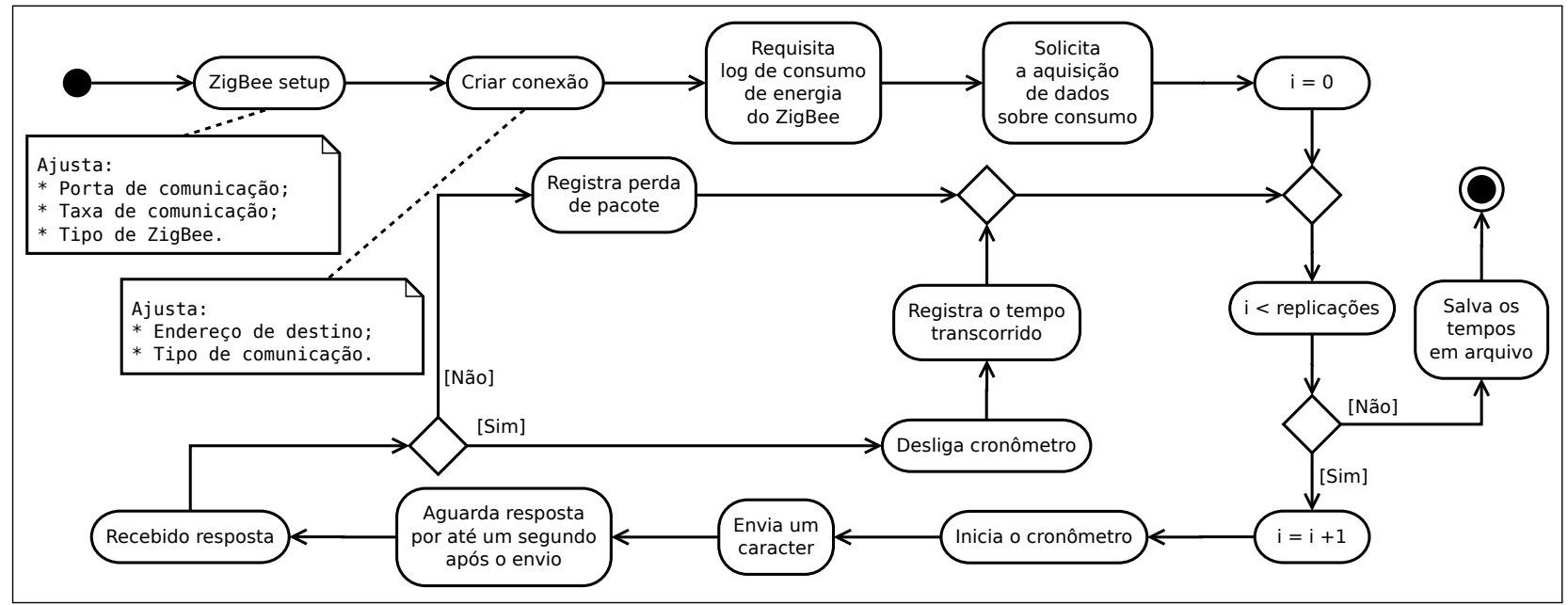

Figura 4.6: Diagrama de atividades do cliente: Procedimento adotado pelo cliente para a realização do experimento.

A Figura 4.9 traz o diagrama de atividades executado no nó servidor, onde este só responde a uma solicitação quando requisitado. 


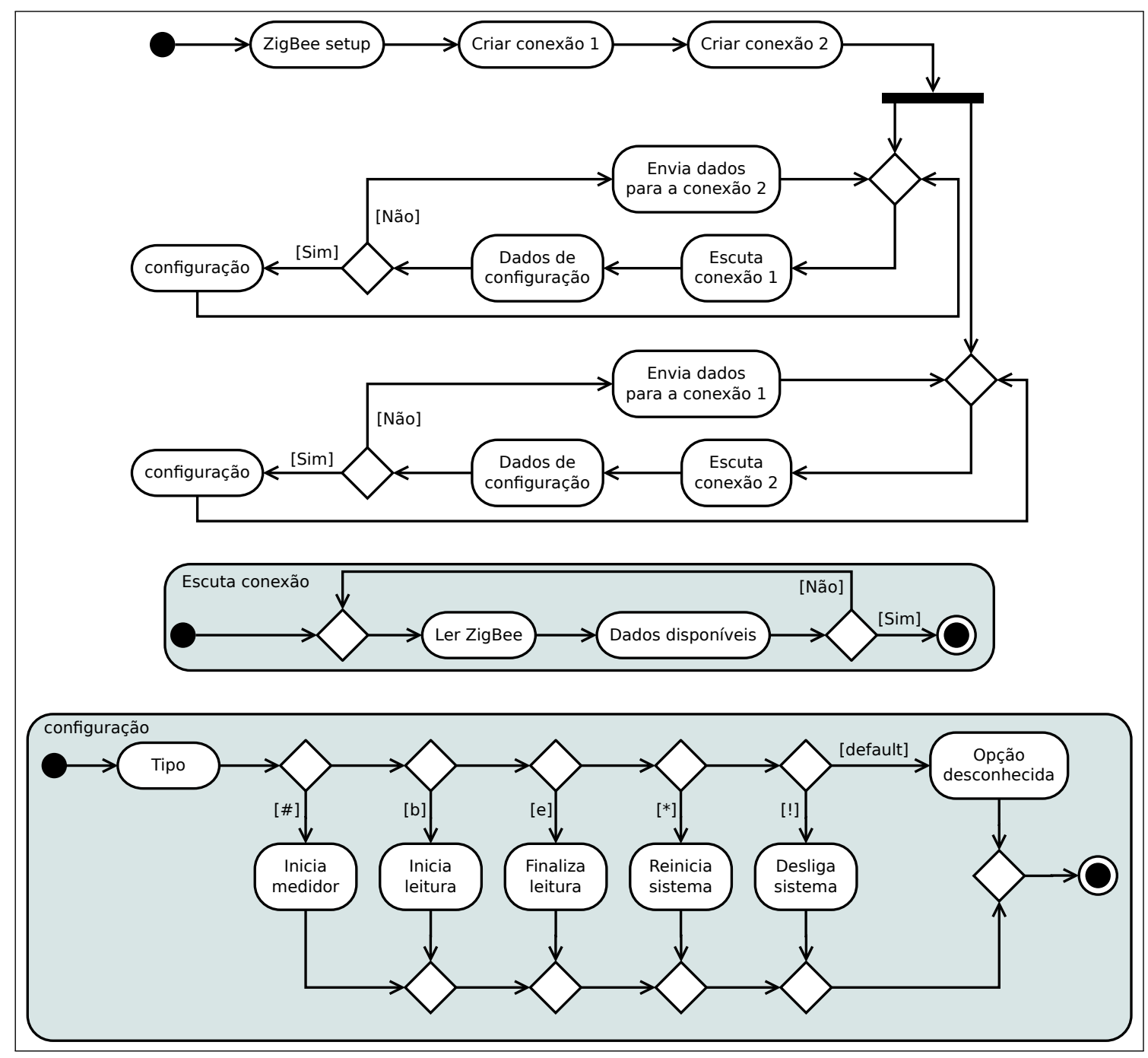

Figura 4.7: Diagrama de atividades do nó volante (Raspberry Pi): Procedimento adotado pelo nó volante para a realização do experimento. 


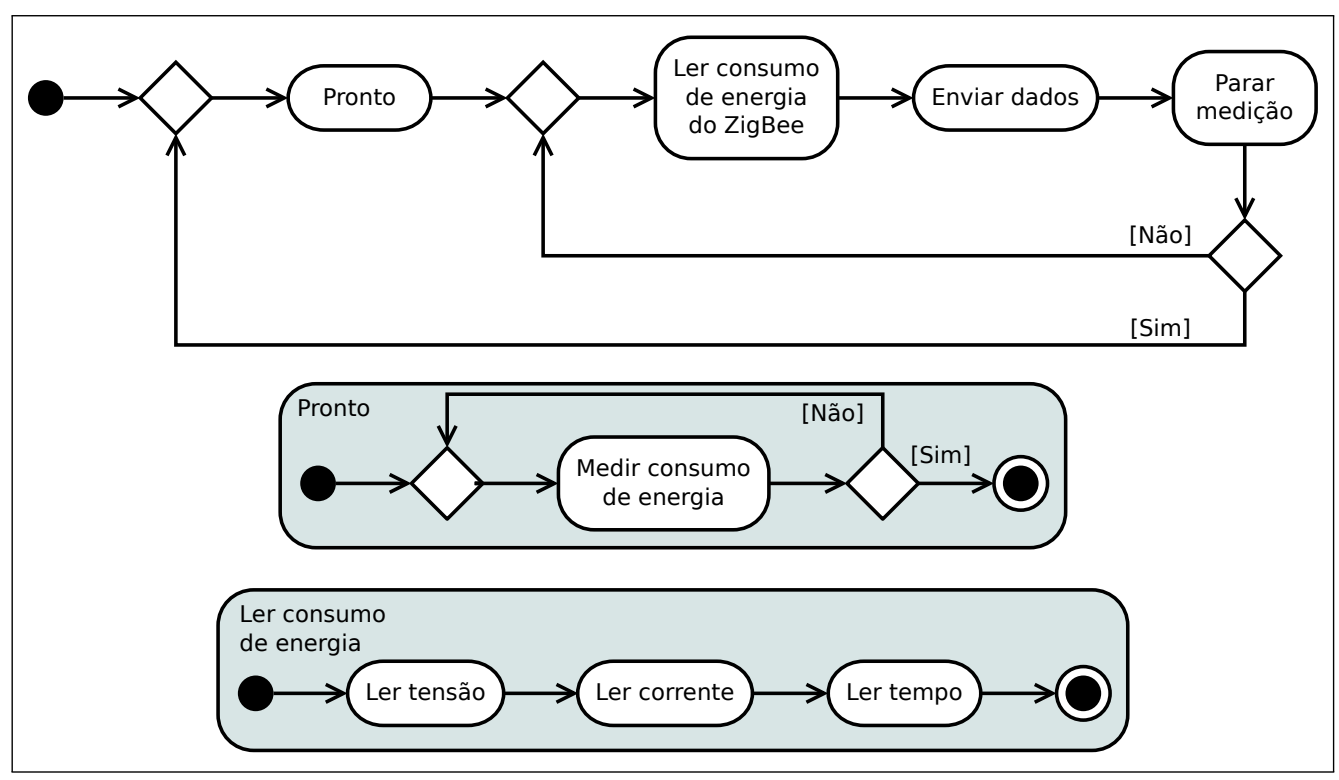

Figura 4.8: Diagrama de atividades do nó volante (Arduino): Procedimento adotado pelo nó volante para a realização do experimento.

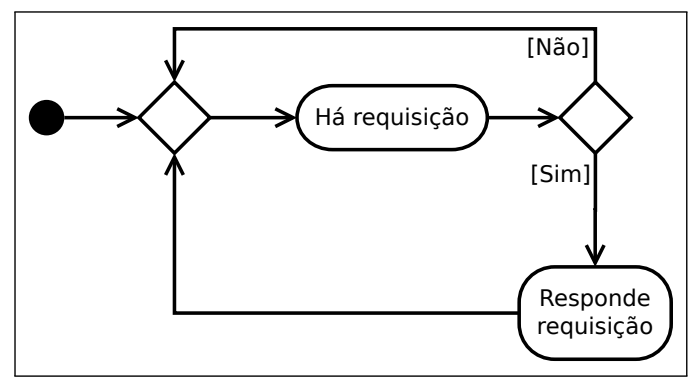

Figura 4.9: Diagrama de atividades do servidor: Procedimento adotado pelo servidor para a realização do experimento. 
Os resultados dos experimentos mostram que as melhores condições de comunicação ocorrem quando o VANT está no ar e quando utiliza uma antena de maior ganho, e que em todas as configurações testadas não houve prejuízo nos tempos de comunicação. O fator que mais afeta o desempenho energético do rádio comunicador é a combinação de altura do VANT e distância entre os nós comunicadores. E os fatores isolados que mais afetam o consumo energético do rádio comunicador são a altura do VANT e o tipo de antena utilizado; O ZigBee mostrou-se muito confiável e não apresentou perdas de pacotes nas comunicações; O estudo qualitativo do consumo energético do VANT mostra que o maior consumo ocorre quando o VANT ganha altura, podendo haver picos muito elevados; O segundo protótipo de nó volante é apresentado, e foi utilizado para a transmissão de imagens de tempo real.

\subsection{Consumo energético do ZigBee}

Com base no planejamento proposto, a Figura 5.1 apresenta os resultados do consumo energético do ZigBee em função do ganho da antena e da distância. Notam-se os menores desvios padrão nos experimentos em que o nó volante está em voo (experimentos E5 a E8), indicando uma concentração de consumo energético perto da média. Os valores dispersos do desvio padrão foram obtidos quando o nó volante estava em solo (experimentos de E1 a E4), isto está relacionado com os resultados do RTT (Figura 5.4). Portanto o desempenho da comunicação sem fio é melhor quando o nó encontra-se mais distante do solo. Isto é obtido mediante o comportamento da propagação de sinais de rádio na atmosfera, influenciados pela reflexão do solo terrestre e é conhecido 
como tow-ray ground-refletion (Ya'acob et al., 2012). Conclui-se que há uma redução do consumo energético do módulo de comunicação ZigBee quando o nó volante está em voo.

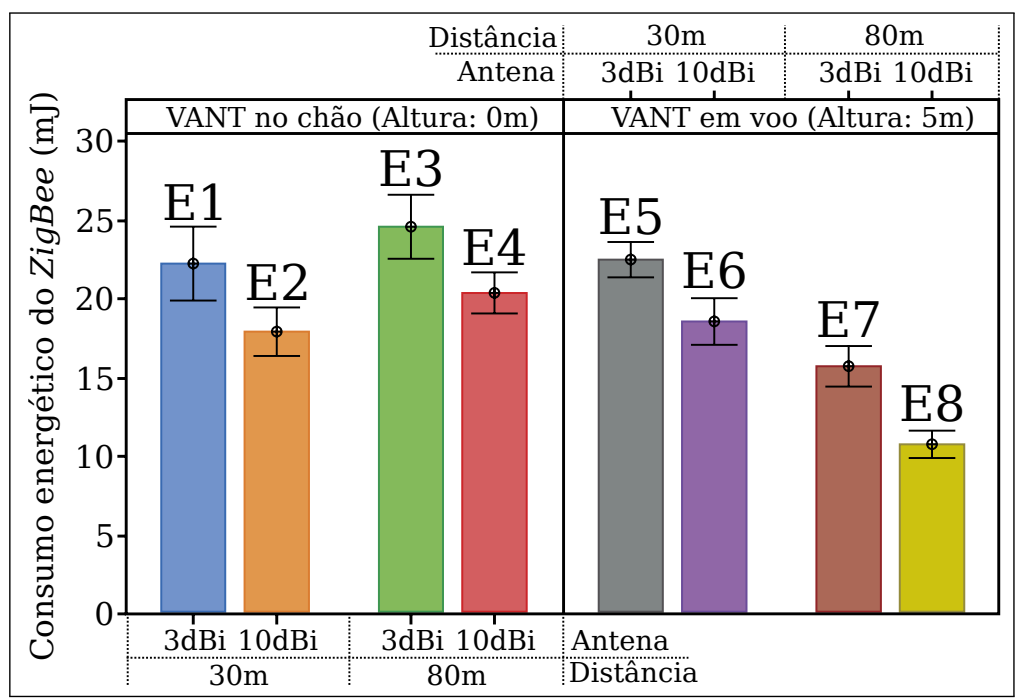

Figura 5.1: Resultados do consumo energético do ZigBee: Menor valor evidencia melhor desempenho, portanto o experimento E8, com antena de maior ganho aliado com o VANT em voo e a uma distância maior entre os comunicadores, obteve melhor desempenho.

A Figura 5.2 mostra o comportamento da interação dos fatores. As linhas paralelas de Altura do VANT e Antena indicam que não houve interação entre esses fatores, ou seja, as médias do consumo energético não foram alteradas com a interação entre o tipo de antena e a altura do nó volante. Nos fatores Antena e Distância, observa-se interação mínima entre eles. Constata-se uma interação significativa entre os fatores Distância e Altura do VANT ao mudar a distância entre os nós de 30 para 80 metros e aumentar a altura do VANT, obtendo-se o melhor resultado.

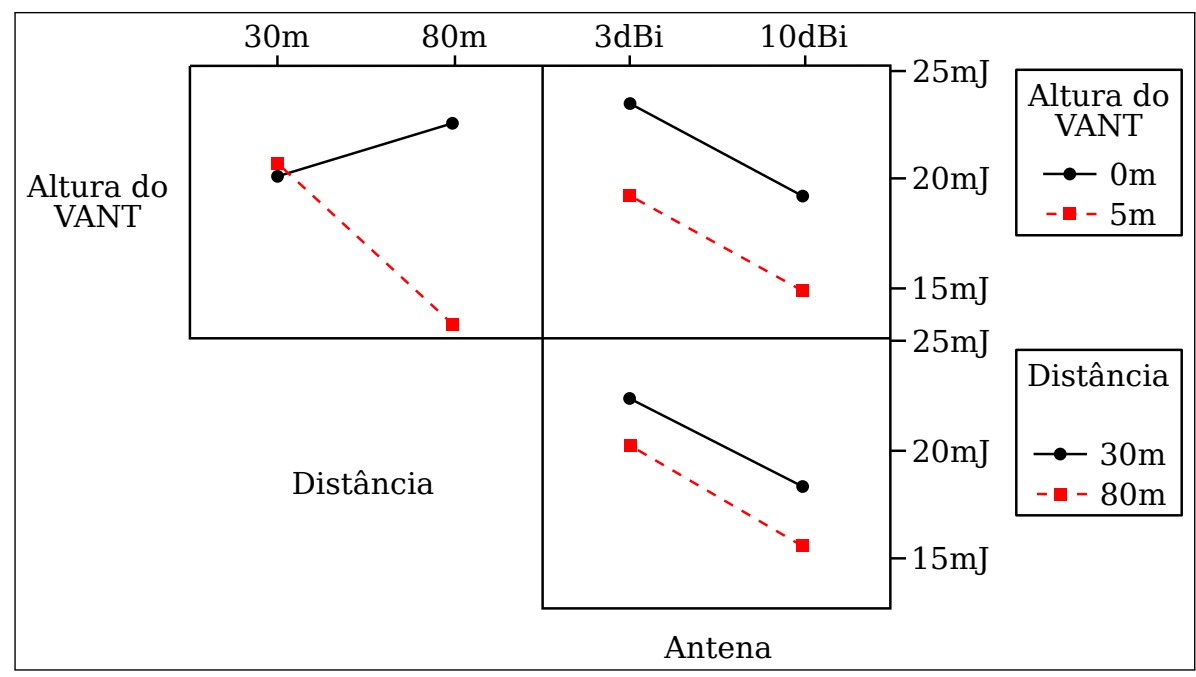

Figura 5.2: Interação entre os fatores no consumo energético do ZigBee: O paralelismo dos efeitos indica ausência de interação entre os fatores. Com isso nota-se que a maior interação entre os fatores ocorre quando altera-se a Altura do VANT e a Distância entre os nós comunicadores. 
De acordo com a Figura 5.3, a combinação dos fatores Altura e Distância é a que causa maior perturbação no consumo energético do ZigBee, além disso outros fatores, como Altura do VANT e Antena também impactam de forma decisiva no consumo energético desse tipo de rádio.

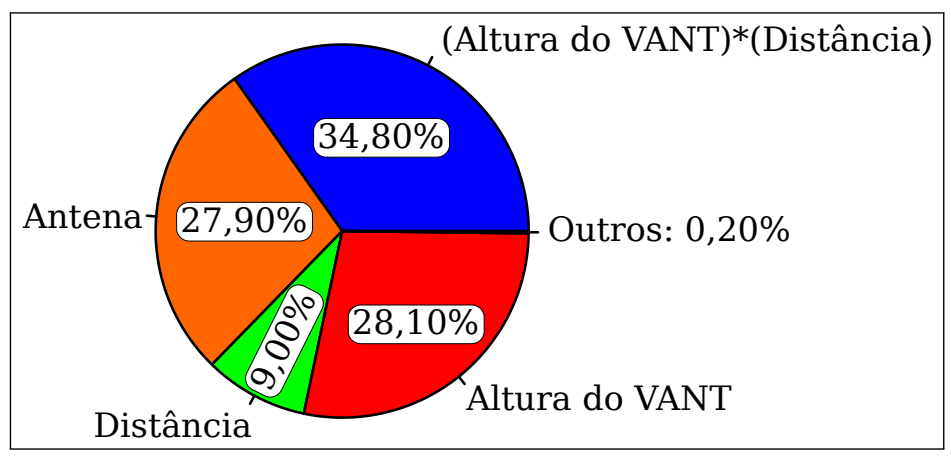

Figura 5.3: Influência dos fatores no consumo energético do ZigBee: A combinação dos fatores Altura e Distância altera significativamente o desempenho do consumo energético do ZigBee. O Fator isolado que mais impacta no consumo energético do ZigBee é a altura do VANT.

\subsection{Round-Trip delay Time (RTT)}

A Figura 5.4 apresenta os resultados do RTT em função do tipo de antena e da distância. Notam-se que os resultados são estatisticamente iguais para todos os casos observados (p-valor é acima de 0,95, no teste de Wilcoxon). Os valores extremos apresentados nos resultados de RTT obedecem a razões de condições ambientais desfavoráveis, como interferências provenientes de sinais WiFi (IEEE802.11), pois WiFi e ZigBee usam a mesma banda de frequência não licenciada de 2.4GHz. Diferentes trabalhos mostram que essa característica interfere no desempenho do ZigBee (Yi et al., 2011). Na análise de valores extremos, não foram considerados valores maiores que $450 \mathrm{~ms}$. Conclui-se que não há prejuízo ou ganho de tempo para as transmissões, nas condições observadas.

A Figura 5.5 traz a interação entre fatores, as linhas paralelas de Altura do VANT e Antena indicam que não houve interação entre eles, ou seja, as médias de RTT não foram alteradas com a interação entre o tipo de antena e altura; o mesmo aconteceu com a interação entre os fatores Altura e Antena. Houve uma pequena interação entre os fatores Distância e Antena.

\subsection{Perda de Pacotes}

Não houve perda de pacote nos oito experimentos (experimento E1 à E8) executados. Isso ocorreu devido às taxas de transferências utilizadas. Como mencionado na Seção 2.2.1 (página 12) a taxa de comunicação entre dois ZigBees é de $250 \mathrm{kbps}$, enquanto que a taxa de comunicação entre o ZigBee e o Raspberry Pi foi de 9,6kbps, uma taxa de transmissão quase 26 vezes menor. Consequentemente, a probabilidade de haver perdas de pacotes é ínfima, dado que o buffer da 


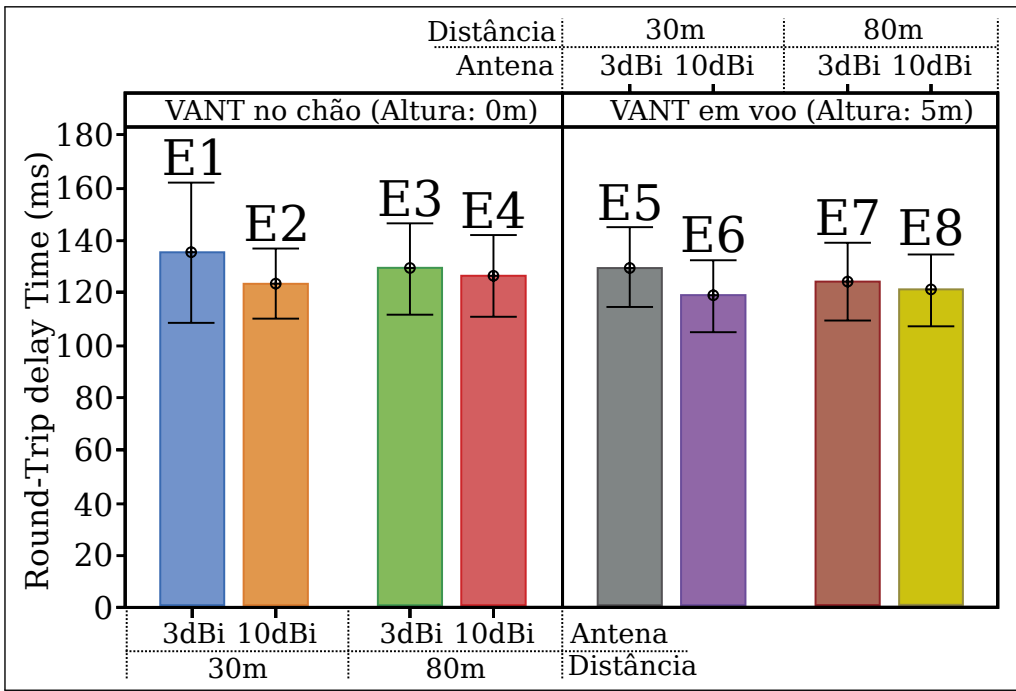

Figura 5.4: Resultados do RTT: Menor valor evidencia melhor desempenho. Nas configurações avaliadas os desempenhos são estatisticamente iguais.

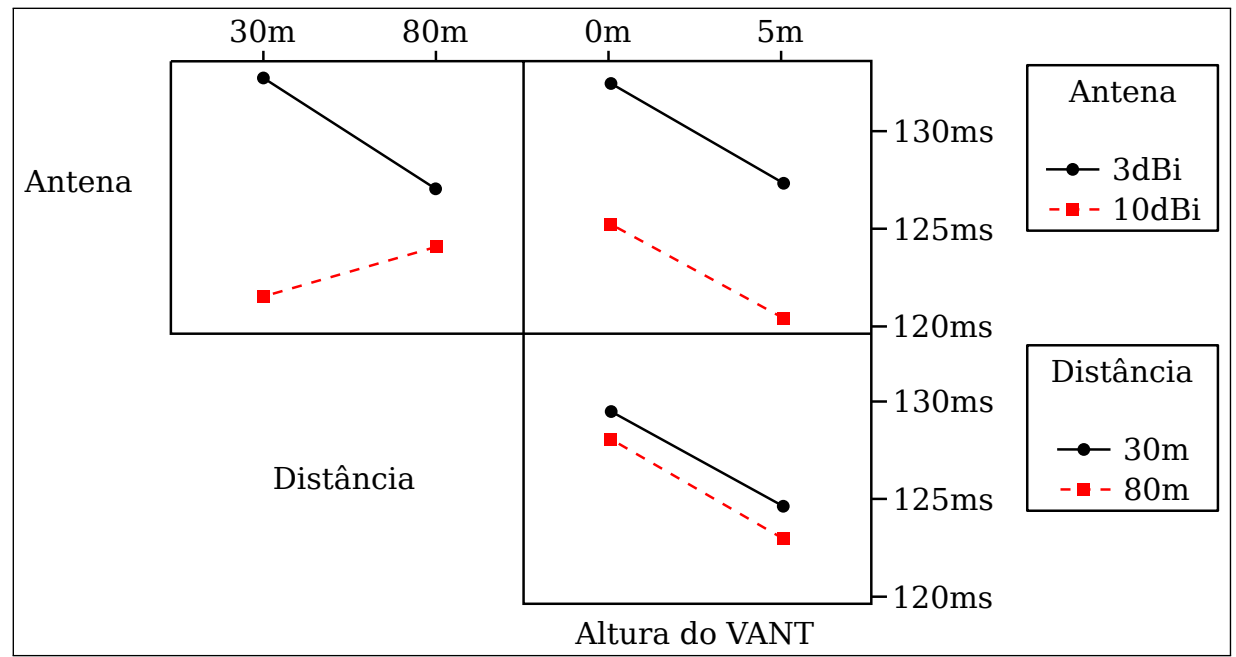

Figura 5.5: Interação entre os fatores no RTT: O paralelismo dos efeitos indica ausência de interação entre os fatores. Portanto, os fatores que apresentam maior interação são Antena e Distância.

UART do Raspberry Pi nunca estoura. A taxa de 9,6kbps foi escolhida por ser a mesma utilizada pela rede e-NOÉ.

A maior taxa de comunicação permitida entre o ZigBee e outro dispositivo (neste caso o Raspberry $P i$ ) é de $115,2 \mathrm{kbps}$, o que representa menos da metade da taxa de comunicação entre dois ZigBees (250kbps). Portanto, os buffers dos ZigBees dificilmente estouram. Ao utilizar o modo API do ZigBee (tal como utilizado nos experimentos deste trabalho), esse tipo de rádio adiciona outras informações ao pacote. Essas informações são adicionadas de acordo com o tipo de pacote, que pode ser dados, configurações locais, ou configurações remotas.

A Tabela 5.1 ilustra as taxas de perdas de pacotes nos experimentos. 
Tabela 5.1: Resultados do RTT: Pacotes recebidos vs. pacotes perdidos

\begin{tabular}{|c|c|c|c|c|c|c|c|c|}
\hline Experimento & E1 & E2 & E3 & E4 & E5 & E6 & E7 & E8 \\
\hline Pacotes recebidos & $100 \%$ & $100 \%$ & $100 \%$ & $100 \%$ & $100 \%$ & $100 \%$ & $100 \%$ & $100 \%$ \\
\hline Pacotes perdidos & $0 \%$ & $0 \%$ & $0 \%$ & $0 \%$ & $0 \%$ & $0 \%$ & $0 \%$ & $0 \%$ \\
\hline
\end{tabular}

\subsection{Consumo Energético do VANT}

Com o objetivo de maximizar a autonomia do nó volante, fez-se um estudo qualitativo do consumo energético do VANT. A Figura 5.6 traz uma amostra dos consumo energético do VANT durante um voo. Dividiram-se essas situações em regiões que são discutidas abaixo:

a) Voo com baixa incidência de vento: As condições observadas são causadas pela passagem de uma corrente de ar leve. Detectou-se um período de instabilidade causado pela passagem do vento através do VANT e, com isso, a necessidade do aumento da rotação das hélices para atenuar a instabilidade, o que resulta no aumento do consumo energético;

b) Voo sem incidência de vento: Condição ideal para a aeronave. Nas condições ideais, o VANT tende a manter seu estado de equilíbrio e sua altura. Neste caso, a redução do consumo energético pode ser observada;

c) Aumento da rotação dos motores para ganhar altura: Nesta situação, há um grande dispêndio de energia elétrica para que o VANT consiga ganhar altitude. Como pode ser observado na Figura 5.6b e 5.6c essa manobra provoca um pico de consumo;

d) Desligamento dos motores: Por padrão, ao desligar os motores há um leve aumento na rotação deles antes de desligados, causando um leve pico na potência consumida;

e) Motores desligados: Situação na qual o consumo é o menor possível.

\subsection{Transmissão de Imagens}

Com o objetivo de melhorar o desempenho de equipes de busca, a transmissão de imagens pode fornecer grande suporte a essas equipes. Para melhorar a qualidade do serviço prestado pelo nó volante, coletaram-se dados de voo e os anexaram nas imagens, como pode ser visto na Figura 5.8, na qual as imagens foram transmitidas por streaming em tempo real. Nessa tarefa, utilizou-se uma rede Wi-Fi com maior largura de banda se comparada com a largura de banda do ZigBee.

A comunicação entre o minicomputador Raspberry Pi e o VANT Mikrokropter foi feita através de uma versão, modificada pelo autor deste trabalho, da biblioteca libmikrokopter (Holz, 2015). Essa adaptação foi necessária devido à incapacidade da bilbioteca original de prover comunicação com o módulo NaviCtrl. 


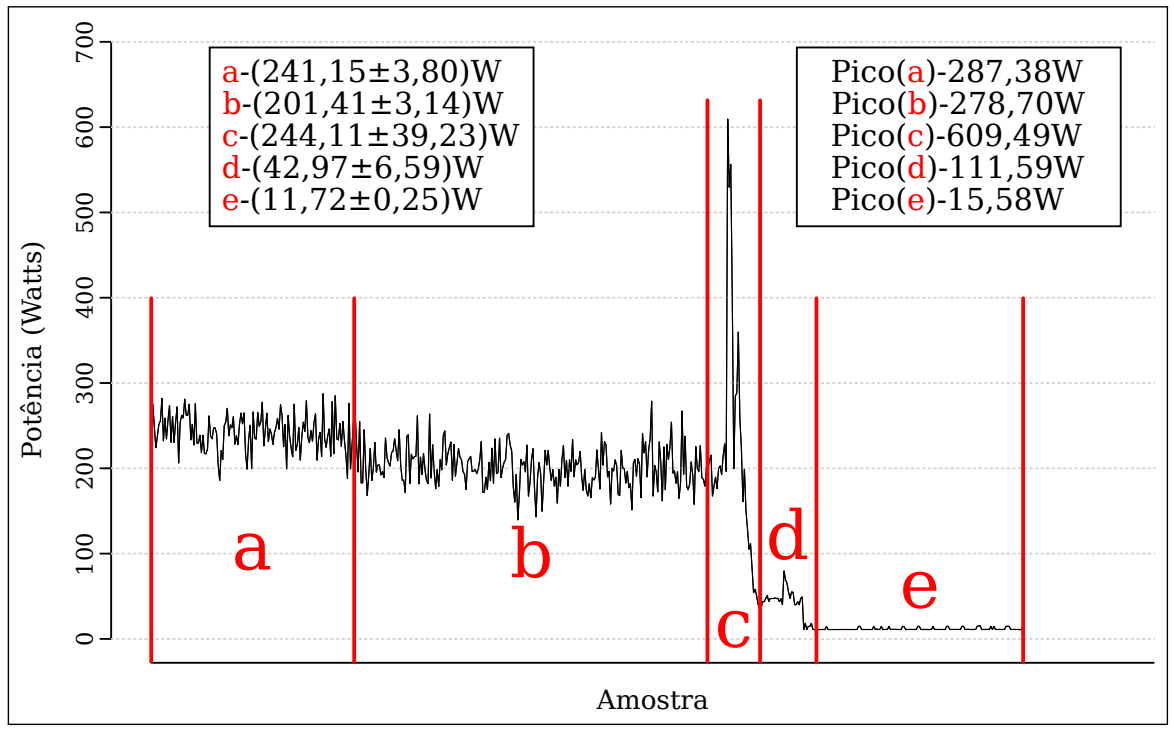

Figura 5.6: Consumo energético do VANT: Análise qualitativa do consumo energético do VANT. O eixo $\mathbf{y}$ representa o consumo energético enquanto que o eixo $\mathbf{x}$ representa o tipo de amostra.: a) Voo com pouco vento; b) Voo sem vento; c) Aumento da rotação dos motores para aumentar a altura; d) Desligamento dos motores; e) Motores desligados.

A Figura 5.7 mostra detalhes do segundo protótipo de nó volante produzido para este trabalho. Confeccionou-se o segundo protótipo com um VANT maior, com oito hélices, que possui uma capacidade de carga maior e aliado a uma maior quantidade de bateria, pode-se prolongar o tempo de voo.

\subsection{Discussão dos Resultados}

De acordo com os objetivos propostos neste trabalho, o protótipo mostrou-se adequado em prover mobilidade ao nó de suporte durante os experimentos de maneira adequada. O nó sensor foi capaz de substituir temporariamente o nó sensor falho durante a comunicação com outros nós sensores sem causar atrasos ou perdas de pacotes. Adicionalmente, estes resultados sugerem uma configuração com antena de maior ganho por causa de seu melhor desempenho, com baixo consumo energético e um alcance de comunicação maior quando o VANT está no ar.

Por outro lado, o consumo de energia do VANT indica a necessidade de uma ação planejada em que o protótipo é usado como uma mula de dados; em outras palavras, para coletar dados sobre o trecho inoperante e transportá-los para uma central de processamento. Deve-se notar que o protótipo não precisa voar exatamente onde os nós sensores foram fixados, uma vez que pode ser possível utilizar uma antena com um ganho maior. Este plano de ação tem um outro aspecto positivo: o protótipo frequentemente retorna à unidade de processamento, o que significa que a sua bateria pode ser carregada quando necessário. 


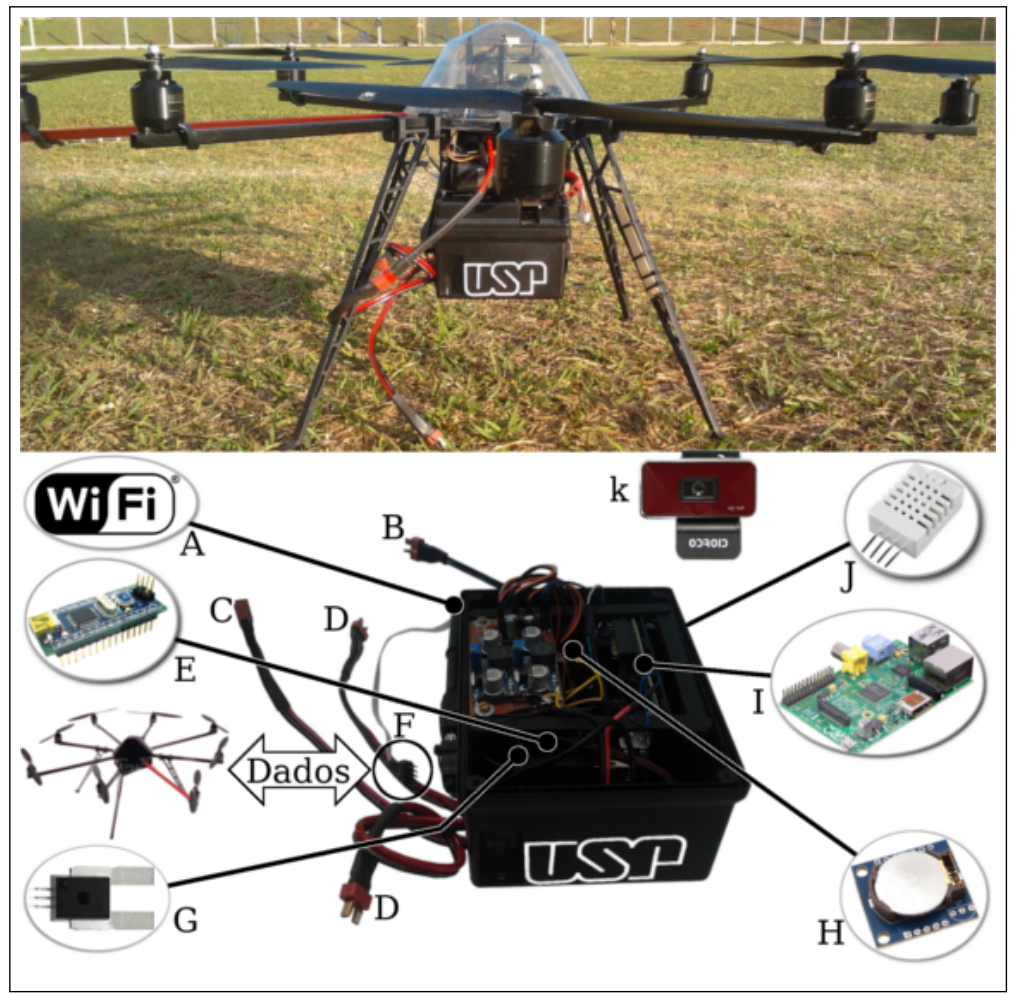

Figura 5.7: Segundo protótipo de nó volante desenvolvido: VANT de oito hélices, com maior capacidade de carga, e versão melhorada do UAV Brain. A) Wi-Fi; B) Plug para alimentação do UAV Brain; C) Plug para alimentação do VANT; D) Plug da bateria do VANT; E) Arduino nano; F) Comunicação entre o UAV Brain e o VANT; G) Sensor de corrente consumida pelo VANT; H) Relógio; I) Raspberry Pi; J) Sensor de umidade e temperatura; K) Câmera.

Um inconveniente da RSSF e-NOÉ é a taxa de transmissão de dados, uma vez que ela opera com ZigBee. A taxa de transmissão de dados numa rede ZigBee é de até 115,2kbps. Com essa taxa de transmissão, não é factível a transmissão de imagens do rio, esse é o motivo pelo qual a rede e-NOÉ transmite apenas texto (i.e. nenhuma imagem é transmitida pela rede ZigBee). Entretanto, o uso do ZigBee é recomendado pelo contexto da aplicação da rede e-NOÉ, um radiotransmissor de longo alcance e baixo consumo energético.

Por esses motivos, realizaram-se testes de transmissão de imagens através da comunicação sem fio Wi-Fi. Como mencionado anteriormente, a transmissão de imagens pode ser útil para que equipes de resgate avaliem as condições do local onde houve o desastre natural, para que com isso, tomem-se medidas mais apropriadas para o enfrentamento da situação.

Por fim, vale lembrar que este método busca explorar o consumo de energia dos nós sensores da RSSF usados para prever enchentes e validar o protótipo proposto de nó volante. Deste modo, pode levar ao desenvolvimento de um plano de ação que visa a proporcionar resiliência para esta arquitetura. 


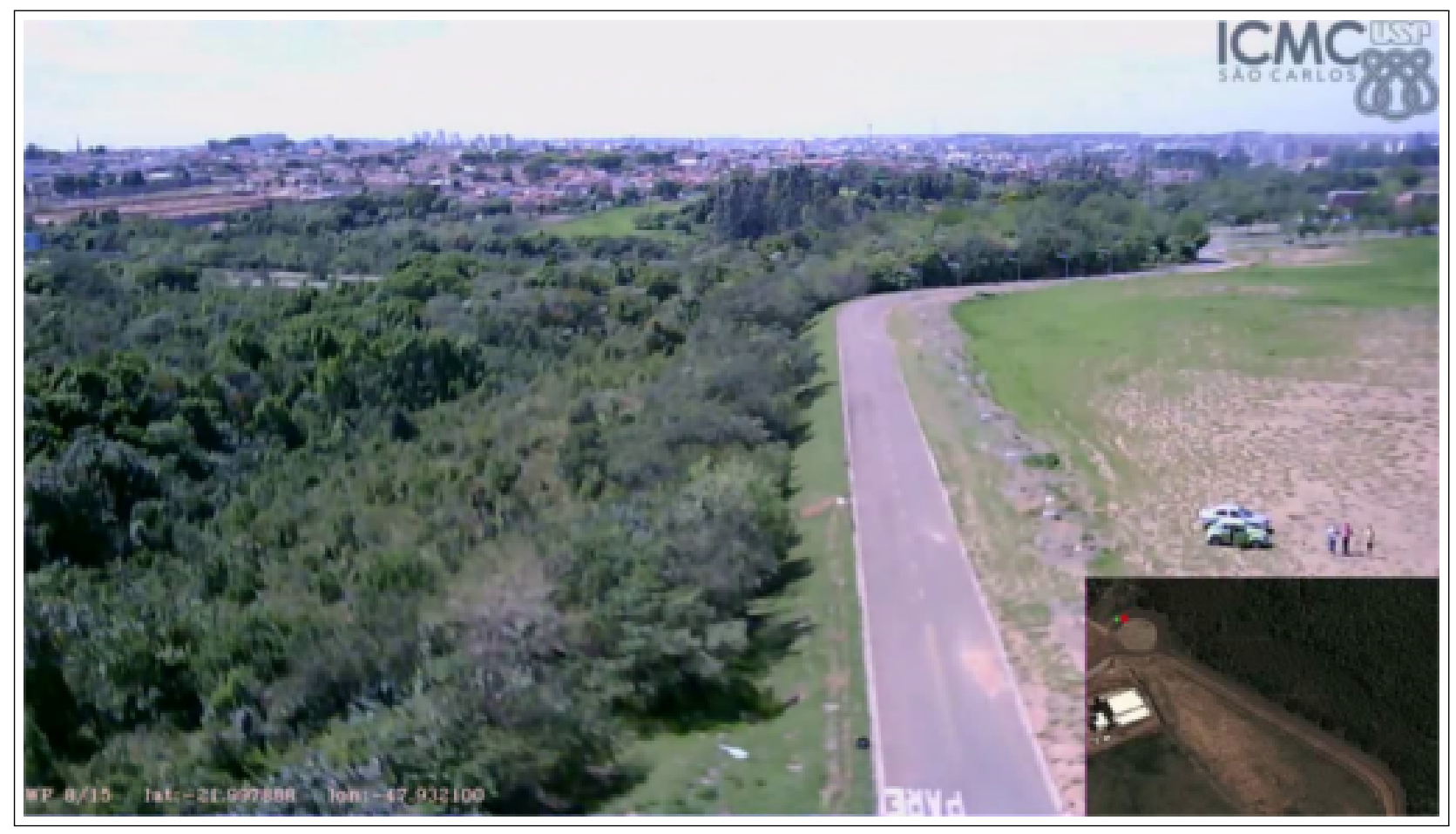

Figura 5.8: Imagens capturadas em voo: Streaming de imagens em tempo real para auxílio de equipes de resgate. No canto inferior direito tem-se uma imagem de satélite para referência, o ponto vermelho indica a localização do VANT enquanto que o ponto verde representa o próximo waypoint de destino. Na parte inferior esquerda têm-se informações de localização e número atual do waypoint. 


$\overline{6}$

Considerações Finais

$\mathrm{E}$ ste trabalho explora o uso de VANT para prover robustez e resiliência a uma rede de sensores sem fio. Conduziu-se uma revisão dos trabalhos relacionados e discutiu-se sobre a literatura da área. Adicionalmente, descreveu-se uma proposta de atuação de um VANT em duas situações chaves em que um VANT pode atuar em caso de falhas de nós de uma RSSF existente.

Conduziram-se experimentos com dispositivos reais, tanto VANT quanto RSSF. A RSSF eNOÉ é capaz de detectar e prever enchentes, mas como a e-NOÉ está instalada em uma região crítica (i.e. áreas em que podem ser alagadas), torna-se altamente propensa a desastres naturais, tais como um dilúvio.

No cumprimento de sua tarefa como um roteador de uma RSSF, o VANT provou ser eficaz, em termos de consumo energético, o que o torna adequado para operar em condições controladas, garantindo portanto, a eficácia das operações da rede em aplicações para detecção de inundações. Realizaram-se experimentos com tempo de propagação dos pacotes (RTT) para mensurar esses tempos de transmissão entre o nó volante e o nó sensor em solo. Esses dados são particularmente importantes para a utilização do nó volante como mula de dados. Adicionalmente, garantiram-se que os tempos de RTT não sofram variações no fluxo de transmissão nas condições examinadas e nas hélices do VANT. Tem-se também a certeza de que não houve perdas de pacotes, de modo que a confiabilidade do ZigBee para o uso de aplicações como o e-NOÉ pode ser avaliado.

Vale frisar que este trabalho inclui experimentos reais, tanto com o VANT quanto a RSSF (i.e., não se utilizaram ferramentas de simulação). Além disso, é importante salientar que a tecnologia de comunicação sem fio testada é capaz de transmitir pacotes sob condições adversas (como chuvas torrenciais), constatadas pela RSSF e-NOÉ. O VANT foi equipado com o rádio ZigBee, mesma 
tecnologia utilizada pela RSSF e-NOÉ para comunicação sem fio. Portanto, acredita-se que o nó volante desenvolvido seja capaz de reestabelecer a comunicação da rede em caso de falha de nós sensores e também servir como mula de dados para fornecer à RSSF um alto grau de resiliência durante desastres naturais.

Esta arquitetura pode ser estendida para outros tipos de desastres, como deslizamentos de terras, que podem ocasionar um grande número de vítimas. VANTs podem ser utilizados nesse cenário para ajudar a reduzir o número de vítimas. Por exemplo, se um sensor detecção/predição de deslizamento de terras falhar em um momento crítico (ou seja, quando o solo alcançar um grau de umidade, ou um determinado limiar), o VANT pode ser acionado para atuar como uma ponte entre os nós funcionais.

Da mesma forma, no âmbito da gestão de desastres, o VANT pode colaborar com a mitigação de acidentes de automóveis e/ou congestionamentos em ruas e avenidas durante seu monitoramento. O VANT pode também enviar imagens, através de uma câmera embutida e realizar o processamento dessas imagens com o intuito de disseminar informações sobre acidentes e tráfego transmitindo-as para veículos e para partes interessadas (i.e. postos policias). Atualmente, há vários dispositivos com boa capacidade computacional, como Beaglebone e ODROID (além do próprio Raspberry $\mathrm{Pi}$ ) os quais são capazes de lidar com o processamento de imagens.

\subsection{Principais contribuições deste trabalho}

Este trabalho produziu algumas contribuições científicas e técnicas. Essas contribuições são importantes para a continuação deste projeto, bem como para trabalhos relacionados os quais podem aproveitar os conhecimentos aqui produzidos e validados. As principais contribuições deste trabalho são apresentadas a seguir.

1. Proposta de uma arquitetura para resiliência em RSSF através de VANT: A resiliência vai além da tolerância a falhas, pois a tolerância a falhas permite que o sistema consiga contornar uma dificuldade encontrada, ao passo que a resiliência permite ao sistema se recuperar de uma anomalia. A arquitetura aqui proposta permite mais confiabilidade a uma RSSF de missão crítica, como a e-NOÉ;

2. Avaliação do consumo energético do dispositivo de rádio embarcado no VANT: Mostra possíveis configurações para minimizar o consumo energético desse dispositivo e com isso, alcançar maior autonomia de voo do VANT. Mostra que os fatores que mais contribuem para a alteração no consumo energético do ZigBee são a altura do VANT e o tipo de antena, respectivamente. Com isso, há uma economia substancial de energia elétrica na transmissão de dados quando o VANT está em voo e quando se utiliza uma antena de maior ganho.

3. Estudo do consumo energético do nó volante: $\mathrm{O}$ entendimento do consumo energético pode levar a melhores estratégias para aumentar a autonomia de voo. A permanência do 
VANT no ar pode ser crucial para o cumprimento de uma missão, como em missões humanitárias.

4. Planejamento de experimentos para quantificar a qualidade do sistema como um todo: Aplicação do método de planejamento de experimentos (em inglês Design of experiments DOE) para prova matemática da viabilidade da proposta e apontamento de melhores possibilidades a serem empregadas.

5. Mecanismo confiável baseado em Arduino para coleta de dados de consumo energético: Garantia de maior precisão no monitoramento energético, pois é um dispositivo baseado em eventos e possui grande escalabilidade de aplicações, uma vez que é programável e aberto. Há resultados publicados em três artigos;

6. Estudo analítico sobre a comunicação sem fio entre sensores em terra e VANT: Útil para o direcionamento de estudos em comunicação sem fio entre VANTs e nós instalados em solo. Mostra que as comunicações ocorrem em condições mais favoráveis quando o VANT está em voo e que não há prejuízo no RTT. Faz uma análise energética e temporal.

7. Desenvolvimento de nó volante baseado em VANT: Possibilita infraestrutura para novos estudos com VANTs bem como na interação de comunicações entre aeronaves e outros dispositivos. Útil para a produção de novos experimentos e contribui com um modelo de testbed ${ }^{1}$ para replicação de experimentos.

\subsection{Trabalhos Futuros}

Vislumbra-se a continuação deste trabalho através dos seguintes tópicos:

- Elaboração de mecanismos para predição da duração da bateria do nó volante, com o objetivo de fornecer dados para um planejamento adequado de voo;

- Utilização de outras antenas de diferentes ganhos para que se possa minimizar as distâncias percorridas pelo nó volante;

- Métodos evolucionários podem ser empregados para que se planeje as locomoções do nó volante quando atuarem como mula de dados.

\footnotetext{
${ }^{1}$ Plataforma para a realização de testes rigorosos, transparentes e replicáveis das teorias científicas, ferramentas computacionais e novas tecnologias.
} 


\subsection{Produção Acadêmica}

Esta seção traz artigos e prêmio conquistado pelo autor deste trabalho ao longo de seu programa de Mestrado. Alguns artigos estão diretamente relacionados a este trabalho e outros estão em outro escopo, mas todos eles foram de fundamental importância para a formação do autor deste trabalho.

\subsubsection{Exploiting the use of unmanned aerial vehicles to provide re- silience in wireless sensor networks - Journal Qualis A1}

O artigo (Ueyama et al., 2014) é derivado deste trabalho e foi publicado na edição de Dezembro de 2014 da IEEE Communications Magazine. Essa revista científica é de grande prestígio no cenário internacional, é qualificada pela CAPES com Qualis Al e possui fator de impacto de 4,46. A Editora Springer fez um convite para os autores escreverem um livro sobre o assunto.

\subsubsection{GuideMe Project - Simpósio}

Esse projeto fez da equipe do ICMC/USP a campeã do IV Simpósio Brasileiro de Engenharia de Sistemas Computacionais (SBESC), disputado por 254 equipes. Esse projeto visa ampliar a autonomia de locomoção para deficientes visuais (Cayres, 2015). Consiste numa mochila inteligente composta por sensores de distância e uma câmera.

Os sensores de distância formam um radar baseado em ecolocalização, semelhante ao sistema utilizado por alguns animais para localização de presas e obstáculos, como morcegos. Ao aproximar de obstáculos, fones de ouvido emitem sons de maneira que o deficiente visual possa obter uma noção tridimensional do ambiente ao seu redor. Com isso, a orientação do deficiente visual torna-se mais precisa. Cabe ao sistema de processamento de imagens detectar e identificar rostos pré-cadastrados no sistema. Dessa maneira, o deficiente visual ouve através do fone de ouvido o nome da pessoa reconhecida pelo GuideMe.

Como um dos principais patrocinadores do evento, a premiação da competição coube à Intel, fabricante de processadores. O premio recebido pela equipe do ICMC/USP é uma viagem para conhecer a fábrica da Intel em Santa Clara na Califórnia-EUA.

A participação do autor deste trabalho foi ajudar no dispositivo de ecolocalização. Embora esse projeto não esteja diretamente relacionado com este trabalho, foi importante para a formação do autor na solidificação de seus conhecimentos em sistemas embarcados, mesmo segmento deste trabalho. 


\subsubsection{The use of unmanned aerial vehicles and wireless sensor networks for spraying pesticides - Journal Qualis B1}

Artigo (Faiçal et al., 2014) publicado no 60 Journal of Systems Architecture (JSA). O JSA é um journal que cobre todos os aspectos de design, arquitetura e software relacionados a sistemas embarcados.

Esse trabalho propõe e avalia uma arquitetura para pulverização agrícola baseada em VANT. O sistema é dividido em dois agentes principais: o VANT, responsável pela pulverização do agrotóxico, e uma RSSF em solo, para fornecer informações de condições climáticas e concentrações do agrotóxico pulverizado. De posse dessas informações, o VANT pode, ou não, corrigir sua rota para que a pulverização ocorra de forma a desperdiçar o mínimo de agrotóxico com o mínimo de impacto ambiental. Os resultados mostram que com os dados providos pela RSSF, houve uma redução drástica no consumo do insumo emitido.

A contribuição do autor deste projeto foi na elaboração e implementação do mecanismo de comunicação entre o VANT e a RSSF instalada em solo. Essa comunicação baseou-se em ZigBee, mesma tecnologia utilizada pelo e-NOÉ e por este projeto. Embora esse artigo não esteja na mesma linha deste projeto, essa atuação trouxe conhecimentos imprescindíveis para a realização deste projeto, uma vez que o artigo e este projeto utilizam comunicação via rádio ZigBee.

\subsubsection{A Study Case of Restful Frameworks in Raspberry Pi: A Per- formance and Energy Overview - Conferência Qualis A1}

Artigo publicado no IEEE International Conference on Web Services 2014 (ICWS). (Nunes et al., 2014a) analisa o comportamento de execução de serviços web em dispositivos com recursos limitados. Os experimentos comparam os serviços web baseados nos frameworks Axis2 e CXF nos quais foram analisados desempenho e consumo energético. Para determinar qual o framework é o mais adequado para a prestação de serviços, um ambiente de teste e uma avaliação de desempenho energético entre eles foram avaliados. Mostrou-se que o Raspberry Pi pode ser útil em aplicações orientadas a serviços para diferentes tipos de tarefas. Reunindo as melhores características de pequenos dispositivos e SoC é possível fornecer diversas, móveis e aplicações verdes.

A contribuição do autor deste projeto foi no emprego do Power monitor (dispositivo formado por Arduino e Power meter shield) para monitoramento energético do Raspberry Pi. Embora esse artigo também não esteja diretamente relacionado a este projeto, os conhecimentos sobre monitoramento energético adquiridos pelo autor deste trabalho foram fundamentais para viabilizar esse artigo e mostrar a escalabilidade do método desenvolvido para monitoramento do consumo energético para este trabalho. 


\subsubsection{Performance and Energy Evaluation of RESTful Web Services in Raspberry Pi - Conferência Qualis B1}

Artigo publicado no IEEE International Performance, Computing, and Communications Conference (IPCCC) 2014. (Nunes et al., 2014b) faz uma análise do consumo energético de frameworks Axis2 e CXF para utilização em sistemas embarcados, em especial o Raspberry Pi. Os resultados mostraram que a cuidadosa seleção de ambientes de desenvolvimento pode fazer diferença significativa no desempenho e consumo de energia.

A contribuição do autor deste projeto também foi no emprego do Power monitor (dispositivo formado por Arduino e Power meter shield) para monitoramento energético do Raspberry Pi. Embora esse artigo não esteja diretamente relacionado a este projeto, assim como no caso anterior, os conhecimentos sobre monitoramento energético adquiridos pelo autor deste trabalho foram fundamentais para viabilizar esse artigo e mostrar a escalabilidade do método desenvolvido para monitoramento do consumo energético para este trabalho. 
Akyildiz, I. F.; Su, W.; Sankarasubramaniam, Y.; Cayirci, E. Wireless sensor networks: a survey. Computer Networks, v. 38, n. 4, p. 393 - 422, 2002.

AKYILDIZ, I. F.; VURAN, M. C. Wireless sensor networks. Wiley, 2010.

ANAC INSTRUÇÃO SUPLEMENTAR - $\quad$ IS $\quad$ No 21-002. http://www2.anac.gov.br/biblioteca/IS/2012/IS\%2021002A.pdf, acessado em 21 de Novembro de 2014., 2012.

ARDUINO Getting started with arduino. http://www.arduino.cc. Visitado em 04 de Fevereiro de 2014., 2014.

DisponÃvel em: http://www.arduino.cc

ATtIE libxbee web site. https://code.google.com/p/libxbee/. Visitado 04 de Fevereiro de 2014, 2014.

DisponÃvel em: https: / / code.google.com/p/libxbee/

Basha, E. A.; RaVEla, S.; Rus, D. Model-based monitoring for early warning flood detection. In: Proceedings of the 6th ACM conference on Embedded network sensor systems, SenSys '08, New York, NY, USA: ACM, 2008, p. 295-308 (SenSys '08, ).

Braun, T.; Heissenbüttel, M.; Roth, T. Performance of the beacon-less routing protocol in realistic scenarios. Ad Hoc Networks, v. 8, n. 1, p. 96 - 107, 2010.

Burleigh, S.; Hooke, A.; Torgerson, L.; Fall, K.; Cerf, V.; Durst, B.; Scott, K.; WEISS, H. Delay-tolerant networking: an approach to interplanetary internet. Communications Magazine, IEEE, v. 41, n. 6, p. 128-136, 2003.

CAYres, F. Agência usp - sistema permite a identificação de ambiente pelo som. http://www.usp.br/agen/?p=194396Janeiro de 2015., 2015. 
Daniel, K.; Dusza, B.; Lewandowski, A.; Wietfeld, C. Airshield: A system-of-systems muav remote sensing architecture for disaster response. In: Systems Conference, 2009 3rd Annual IEEE, 2009, p. 196-200.

Dios, J. R.; Lferd, K.; SAn Bernabé, A.; Núñez, G.; Torres-GonzÁlez, A.; Ollero, A. Cooperation between uas and wireless sensor networks for efficient data collection in large environments. Journal of Intelligent \& Robotic Systems, v. 70, n. 1-4, p. 491-508, 2013.

E-NOÉ Geodashboard: Monitoramento dos rios de são carlos. http://www.agora.icmc.usp.br:8080/AgoraSADEv2, acessado em 28 de Janeiro de 2015., 2015.

Erman, A.; Hoesel, L.; HaVinga, P.; Wu, J. Enabling mobility in heterogeneous wireless sensor networks cooperating with uavs for mission-critical management. Wireless Communications, IEEE, v. 15, n. 6, p. $38-46,2008$.

EROL-KANTARCI, M.; Mouftah, H. Wireless sensor networks for smart grid applications. In: Electronics, Communications and Photonics Conference (SIECPC), 2011.

Faiçal, B. S.; Costa, F. G.; Pessin, G.; Ueyama, J.; Freitas, H.; Colombo, A.; Fini, P. H.; VIllas, L.; Osório, F. S.; VARGAS, P. A.; BraUn, T. The use of unmanned aerial vehicles and wireless sensor networks for spraying pesticides. Journal of Systems Architecture, v. 60, n. 4, p. $393-404,2014$.

DisponÃvel em: http://www.sciencedirect.com/science/article/pii/ S1383762114000204

FARAHANI, S. Zigbee basics. in: Zigbee wireless networks and transceivers. Access Online via Elsevier, 4-6 p., 2011.

FERREIRA, M. Raspberry pi foi usado para controlar um r2-d2 interactivo. http://www.pcmanias.com/ raspberry-pi-foi-usado-para-controlar-um-r2-d2-interactivo/.

Visitado em 04 de Fevereiro de 2014., 2013.

DisponÃvel em: http: //www.pcmanias.com/raspberry-pi-foi-usado-para-controlar-

FInN, A.; SCHEDIng, S., eds. Developments and challenges for autonomous unmanned vehicles. Verlag Berlin Heidelberg: Springer, 2010.

Freitas, E. P.; Heimfarth, T.; Netto, I. F.; Lino, C. E.; Pereira, C. E.; Ferreira, A. M.; Wagner, F. R.; Larsson, T. Uav relay network to support wsn connectivity. 2010.

GASCón, D. 802.15.4 vs zigbee. http://sensor-networks.org/index.php? page $=0823123150$. Visitado em 04 de Fevereiro de 2014., 2008.

DisponÂvel em: http: / / sensor-networks . org/index .php?page=0 823123150 
Gislason, D. Hello zigbee. in: Zigbee wireless networking. Newnes, 9 p., $2008 \mathrm{a}$.

GiSLASON, D. Zigbee wireless networking. Newnes, 2008b.

HAlfacree, G.; Upton, E. Raspberry pi user guide. Wiley, 2012. DisponÃvel em: http: //books.google.com.br/books? id=h4odLCArZAEC

Halkes, G. P.; Dam, T.; Langendoen, K. G. Comparing energy-saving mac protocols for wireless sensor networks. Mob. Netw. Appl., v. 10, p. 783-791, 2005.

Hauert, S.; Leven, S.; Zufferey, J.-C.; Floreano, D. Communication-based swarming for flying robots. In: International Workshop on Self-Organized System, Zurich, Switzerland, 2010.

HEKKERs, R. Working on zigbee api mode interface. http://blog.hekkers.net/ 2009/12/18/working-on-zigbee-api-mode-interface. Visitado em 04 de Fevereiro de 2014, 2009.

DisponÃvel em: http://blog.hekkers.net/2009/12/18/ working-on-zigbee-api-mode-interface

Holz, D. A simple c++ library for communicating with mikrokopter micro aerial vehicles. https://github.com/dirkholz/libmikrokopter, acessado em 28 de Janeiro de 2015., 2015.

Hughes, D. The gridstix flood prediction system. 14,23 p., 2008.

Hughes, D.; Ueyama, J.; Mendiondo, E.; Matthys, N.; Horré, W.; Michiels, S.; Huygens, C.; Joosen, W.; Man, K. L.; GuAn, S.-U. A middleware platform to support river monitoring using wireless sensor networks. Journal of the Brazilian Computer Society, Springer, v. 17, n. 2, p. 85-102, 2011.

HW Kitchen Gsm playground - gsm shield. http://www.hwkitchen.com/products/gsmplayground, acessado em 28 de Janeiro de 2015., 2015.

IEEE Ieee 802.11 wlan. http: / / www. ieee802. org/11. Visitado em 04 de Fevereiro de 2014., 2014a.

DisponÃvel em: http://www.ieee802.org/11/

IEEE Ieee 802.3 ethernet. http: / / www. ieee802. org/3/. Visitado em 04 de Fevereiro de 2014., 2014b.

DisponÃvel em: http: / / www . ieee802.org/3/

Juang, P.; OKi, H.; Wang, Y.; Martonosi, M.; Peh, L. S.; Rubenstein, D. Energyefficient computing for wildlife tracking: design tradeoffs and early experiences with zebranet. SIGOPS Oper. Syst. Rev., v. 36, n. 5, p. 96-107, 2002. 
KEANE, J. F.; CARR, S. S., eds. A brief history of early unmanned aircraft. Jhons Hopkins, 2013.

Kim, Y.; Schmid, T.; Charbiwala, Z. M.; Friedman, J.; Srivastava, M. B. Nawms: Nonintrusive autonomous water monitoring system. 2008.

KUPPER, A. Basic of wireless communications. in: Location-based services. Wiley Online Library, 68 p., 2005.

LI, B.; LIU, R.; LIU, S.; LIU, Q.; LIU, F.; ZHOU, G. Monitoring vegetation coverage variation of winter wheat by low-altitude uav remote sensing system. Nongye Gongcheng Xuebao/Transactions of the Chinese Society of Agricultural Engineering, v. 28, n. 13, p. 160 - 165, 2012.

DisponÂvel em: http://dx.doi.org/10.3969/j.issn.1002-6819.2012.13. 026

Lorincz, K.; Welsh, M.; Marcillo, O.; Johnson, J.; Ruiz, M.; Lees, J. Deploying a wireless sensor network on an active volcano. In: IEEE Internet Computing, 2006, p. 18-25.

Malan, D.; Fulford-Jones, T.; Welsh, M.; Moulton, S. Codeblue: An ad hoc sensor network infrastructure for emergency medical care. In: In International Workshop on Wearable and Implantable Body Sensor Networks, 2004.

Marinho, M.; Freitas, E.; Costa, J.; Almeida, A.; Sousa, R.T., J. Using cooperative mimo techniques and uav relay networks to support connectivity in sparse wireless sensor networks. In: Computing, Management and Telecommunications (ComManTel), 2013 International Conference on, 2013, p. 49-54.

MikroKopter Mikrokopter. http://www.mikrokopter. de/. Visitado em 04 de Fevereiro de 2014., 2014a.

DisponÂvel em: http: / / www.mikrokopter.de/

MikroKopter Mikrokopter flightsystems. http://www.mikrokopter.de/en/ products / flightsystems. Visitado em 04 de Fevereiro de 2014., 2014b.

DisponÃvel em: http: //www.mikrokopter.de/en/products/flightsystems

MikroKopter Mikrokopterwiki. http://wiki.MikroKopter.de/en/FlightCtrl_ME_2_1, acessado em 28 de Janeiro de 2015., 2015a.

MikroKopter Mikrokopterwiki. http://wiki.MikroKopter.de/en/NaviCtrl_2.0, acessado em 28 de Janeiro de 2015., 2015b.

Morgenthaler, S.; Braun, T.; Zhao, Z.; Staub, T.; Anwander, M. Uavnet: A mobile wireless mesh network using unmanned aerial vehicles. 2012. 
NiCUlesCU, D. Communication paradigms for sensor networks. Communications Magazine, IEEE, v. 43, n. 3, p. 116 - 122, 2005.

Nunes, L.; VAsconcelos NaKamura, L.; F Vieira, H.; O Libardi, R.; Oliveira, E.; Junqueira AdAmi, L.; Estrella, J.; ReifF-MARganiec, S. A study case of restful frameworks in raspberry pi: A performance and energy overview. In: Web Services (ICWS), 2014 IEEE International Conference on, 2014a, p. 722-724.

Nunes, L. H.; NAKamura, L. H.; Vieira, H. D. F.; Libardi, R. M. O.; Oliveira, E. M.; Estrella, J. C.; Reiff-MarganieC, S. Performance and energy evaluation of restful web services in raspberry pi. In: Performance Computing and Communications Conference (IPCCC), 2014 IEEE International, 2014b, p. 1-9.

RASPBERRY Pi FOUNDATION Faqs raspberry pi. http://www.raspberrypi.org/ faqs\# softwarelanguages. Visitado em 04 de Fevereiro de 2014., 2014.

DisponÂvel em: http: / /www.raspberrypi .org/faqs\#softwareLanguages

SENA Zigbee technology overview. http://www.sena.com/products/ industrial_zigbee/zigbee_summary.php. Visitado em 04 de Fevereiro de 2014., 2011.

DisponÃvel em: http://www.sena.com/products/industrial_zigbee/ zigbee_summary $\cdot \mathrm{php}$

SiBBALD, B. Use computerized systems to cut adverse drug events: report. Canadian Medical Association Journal (CMAJ), 2001.

Sun, Y.; Wu, C.; ZHANG, Y.; HU, N. Holes detection in wireless sensor network and redeploy route planning based on unmanned aerial vehicle? 2012.

TEAL Group Teal group predict uav market. http://www.tealgroup.com/index.php/abouttealgroupcorporation/pressreleases/1182014uavpressrelease, acessado em 29 de Outubro de 2014., 2014.

Tekdas, O.; Isler, V.; LiM, J. H.; Terzis, A. Using mobile robots to harvest data from sensor fields. Wireless Communications, IEEE, v. 16, n. 1, p. 22-28, 2009.

Tuna, G.; Mumcu, T. V.; Gulez, K.; Gungor, V. C.; Erturk, H. Unmanned aerial vehicle-aided wireless sensor network deployment system for post-disaster monitoring. In: Emerging Intelligent Computing Technology and Applications, Springer, p. 298-305, 2012.

Ueyama, J.; Freitas, H.; Faical, B.; Filho, G.; Fini, P.; Pessin, G.; Gomes, P.; Villas, L. Exploiting the use of unmanned aerial vehicles to provide resilience in wireless sensor networks. Communications Magazine, IEEE, v. 52, n. 12, p. 81-87, 2014. 
Ueyama, J.; Hughes, D.; Man, K. L.; Guan, S.; Matthys, N.; Horré, W.; Michiels, S.; Huygens, C.; Joosen, W. Applying a multi-paradigm approach to implementing wireless sensor network based river monitoring. In: Cryptography and Network Security, Data Mining and Knowledge Discovery, E-Commerce Its Applications and Embedded Systems (CDEE), 2010 First ACIS International Symposium on, 2010, p. 187-191.

VIllas, L. A. SoluÇÕes cientes de agregaÇÃo de dados, da correlaÇÃo espaÇo-temporal e consumo de energia para realizar coleta de dados em redes de sensores sem fio - data aggregation, spatio-temporal correlation and energy-aware solutions to perform data collection in wireless sensor networks. Tese de Doutoramento, Universidade Federal de Minas Gerais UFMG, 2012.

Villas, L. A.; Guidoni, D. L.; Boukerche, A.; Loureiro, A. A.; Ueyama, J. Localização $3 \mathrm{~d}$ em redes de sensores sem fio utilizando veículo aéreo não tripulado. Simpósio Brasileiro de Redes de Computadores e Sistemas Distribuídos, v. '31, 2013.

Warneke, B.; Last, M.; Liebowitz, B.; Pister, K. Smart dust: communicating with a cubic-millimeter computer. Computer, v. 34, n. 1, p. 44-51, 2001.

XiAng, H.; TiAn, L. Development of a low-cost agricultural remote sensing system based on an autonomous unmanned aerial vehicle (uav). Biosystems Engineering, v. 108, n. 2, p. $174-$ 190, 2011.

DisponÂvel em: http://dx.doi.org/10.1016/j.biosystemseng.2010.11. 010

YA' ACOb, N.; Yusop, N.; SharifF, K. K. M.; Yusof, A. L.; Ali, M. T.; SAlleh, M. K. M. Observation of tweek characteristics in the mid-latitude d-region ionosphere, p. 28. 2012.

Yi, P.; IWAYEMI, A.; Zhou, C. Developing zigbee deployment guideline under wifi interference for smart grid applications. Smart Grid, IEEE Transactions on, v. 2, n. 1, p. 110-120, 2011. 